\title{
Expression analysis of secreted and cell surface genes of five transformed human cell lines and derivative xenograft tumors Robert A Stull ${ }^{1}$, Roya Tavassoli ${ }^{1}$, Scot Kennedy ${ }^{1}$, Steve Osborn ${ }^{1}$, Rachel Harte ${ }^{1}$, Yan Lu1 ${ }^{1}$, Cheryl Napier ${ }^{2}$, Arie Abo*1 and Daniel J Chin*1
}

\author{
Address: ${ }^{1 P P D}$ Discovery, 1505 O'Brien Street, Menlo Park, California 94025, USA and 2Piedmont Research Center, Morrisville, North Carolina \\ 27560, USA \\ Email: Robert A Stull - robert.stull@menlo.ppdi.com; Roya Tavassoli - roya.tavassoli@menlo.ppdi.com; \\ Scot Kennedy - scott.kennedy@menlo.ppdi.com; Steve Osborn - steve.osborn@menlo.ppdi.com; Rachel Harte - rachel.harte@menlo.ppdi.com; \\ Yan Lu - yan.lu@menlo.ppdi.com; Cheryl Napier - cheryl.napier@menlo.ppdi.com; Arie Abo* - arieabo@yahoo.com; \\ Daniel J Chin* - daniel.chin@menlo.ppdi.com \\ * Corresponding authors
}

Published: 18 April 2005

BMC Genomics 2005, 6:55 doi:10.1/86/147|-2/64-6-55

This article is available from: http://www.biomedcentral.com/I47I-2/64/6/55

(C) 2005 Stull et al; licensee BioMed Central Ltd.

This is an Open Access article distributed under the terms of the Creative Commons Attribution License (http://creativecommons.org/licenses/by/2.0), which permits unrestricted use, distribution, and reproduction in any medium, provided the original work is properly cited.
Received: 20 September 2004

Accepted: 18 April 2005

\begin{abstract}
Background: Since the early stages of tumorigenesis involve adhesion, escape from immune surveillance, vascularization and angiogenesis, we devised a strategy to study the expression profiles of all publicly known and putative secreted and cell surface genes. We designed a custom oligonucleotide microarray containing probes for 353I secreted and cell surface genes to study 5 diverse human transformed cell lines and their derivative xenograft tumors. The origins of these human cell lines were lung (A549), breast (MDA MB-23I), colon (HCT-I I6), ovarian (SK-OV-3) and prostate (PC3) carcinomas.
\end{abstract}

Results: Three different analyses were performed: (I) A PCA-based linear discriminant analysis identified a 54 gene profile characteristic of all tumors, (2) Application of MANOVA (Pcorr $<.05$ ) to tumor data revealed a larger set of 149 differentially expressed genes. (3) After MANOVA was performed on data from individual tumors, a comparison of differential genes amongst all tumor types revealed 12 common differential genes. Seven of the 12 genes were identified by all three analytical methods. These included late angiogenic, morphogenic and extracellular matrix genes such as ANGPTL4, COLIAI, GP2, GPR57, LAMB3, PCDHB9 and PTGER3. The differential expression of ANGPTL4 and COLIAI and other genes was confirmed by quantitative PCR.

Conclusion: Overall, a comparison of the three analyses revealed an expression pattern indicative of late angiogenic processes. These results show that a xenograft model using multiple cell lines of diverse tissue origin can identify common tumorigenic cell surface or secreted molecules that may be important biomarker and therapeutic discoveries.

\section{Background}

The process of tumorigenesis has long been recognized to depend upon complex interactions of a tumor with its non-transformed tissue environment [1]. Beyond trans- formation and increased proliferation, many pathways are activated both in the growing tumor and its environment to culminate in an established solid tumor. For example, adhesive pathways are activated to enable 
transformed cells to aggregate and form a microtumor. Subsequently, microtumors must avoid destruction by the immune system and elicit vasculature formation for continued growth $[2,3]$. In support of these events, cell-matrix adhesion proteins, cell surface antigens, angiogenic factors and modulatory agents have been found differentially expressed in several experimental models of tumorigenesis [4-6] and in tumor biopsy samples relative to control tissues $[7,8]$. Experimental models with established tumorigenic human cell lines have compared the gene expression profiles between the cultured parental cells and after implantation into immune-deficient murine hosts [6]. In this study, we examined this problem with a more focused approach with respect to the transcripts as well as a broader survey by examining multiple tumor sources in order to identify differential genes common to multiple solid tumors in a xenograft model of tumorigenesis.

To recapitulate the attachment and growth of a micro- or metastatic tumor, our experimental tumorigenesis model examined human xenograft tumors in nude mice. It is believed that primary or metastatic microtumors about 1 $\mathrm{mm}^{3}$ in size are metastable; they are either (i) resolved by the immune system, (ii) remain in a steady-state with balanced proliferation and apoptosis or (iii) undergo aggressive growth as long as a vasculature is developed to provide nutrients to the growing mass [9]. Since the endpoint of the xenograft assay is the formation of a solid tumor, genes supporting vasculogenesis and angiogenesis are likely differentially expressed relative to the parental cell lines that were adapted to culture in vitro. However, the extent of vascularization to support an established tumor will vary according to the tumor type and tissue environment as a result of variable levels of proteases, receptors or regulators of pericyte and/or endothelial migration, proliferation, and differentiation $[3,10]$. Additionally, some tumors such as early grade astrocytomas can leverage existing normal brain blood vessels without substantial vasculogenesis for subsequent angiogenic sprouting of new vessels from preexisting vessels [11]. Further, vascularization depends upon a tuned interaction in the tissue microenvironment between endothelial cells and pericytes $[12,13]$. Vascularization of solid tumors may also be heterogeneous with a rapidly growing margin surrounding a hypoxic core following regression of coopted vessels that supported early tumor growth [10]. Complicating this picture is the potential for Vascular mimicry' where breast tumor derived cells express endothelial markers and may serve as rudimentary channels [14].

Many angiogenesis studies have used cultured primary vascular endothelial cells and shown the significant roles of VEGF, FGF, PDGF, chemokines and cell-matrix adhesion proteins $[3,15,16]$. These assays for endothelial cell migration include the chorioallantoic membrane [17], matrigel migration assays [18] or 3D-collagen assays [19]. However, the limits of studying the angiogenic process with established endothelial cells in vitro have been recognized. Tumorigenesis involves both heterophilic and homophilic cellular communication and adhesion between not only endothelial cells but also pericytes and smooth muscle cells; hence other cell surface proteins and secreted factors are absent from such assays [3].

A search for tumorigenic genes common to tumors of diverse origin should be as broad as possible and hence should not be limited to a single tumor type or tissue source. In order to find common tumorigenic genes regardless of tissue origin, we chose to study a panel of 5 adenocarcinoma cell lines from breast, colon, and lung, ovarian and prostate tumors. These cell lines reproducibly yield solid tumors in a standard xenograft assay in immuno-compromised mice [20-22]. While there may be individual differences in capillary branching or density between tumor types, the xenograft assay requires vascular development to support solid tumor formation in a relatively avascular subcutaneous site.

Since the early tumorigenic events largely rely upon secreted factors, cell surface receptors or integral membrane proteins, we devised a strategy to employ a custom microarray to focus on the expression of genes chosen on the basis of their cellular localization. Hence, we implemented an experimental microarray strategy with high replication and coverage of all possible secreted and cell surface proteins. Also, focusing on all known and predicted cell surface and secreted genes allowed us to design more intra-chip replicates for improved data reliability. While prioritizing on the 'Function' category of the Gene Ontology [23], the range of 'Biological Processes' covered by the gene selection remained broad. In contrast to early concerns that a sub-selection of genes might result in a systemic bias, relatively small numbers of genes were found to be common to all xenograft tumors due to the robust experimental design and statistical analysis.

\section{Results}

We developed a custom 60-mer oligonucleotide microarray to focus on an ontologically restricted set of secreted and cell surface genes for higher data reliability using a matrix design with intra-chip replicates in addition to replicate chips. Due to the limits of the Gene Ontology classification, multiple strategies had to be used to derive a relatively complete collection of secreted and cell surface genes. For example, some proteins have multiple localization sites on the basis of newer experimental evidence absent from curated databases; e.g. SORCS3, HDGF. For proteins with multiple cellular localizations, the literature (PubMed, NCBI) was the annotation source for finding 


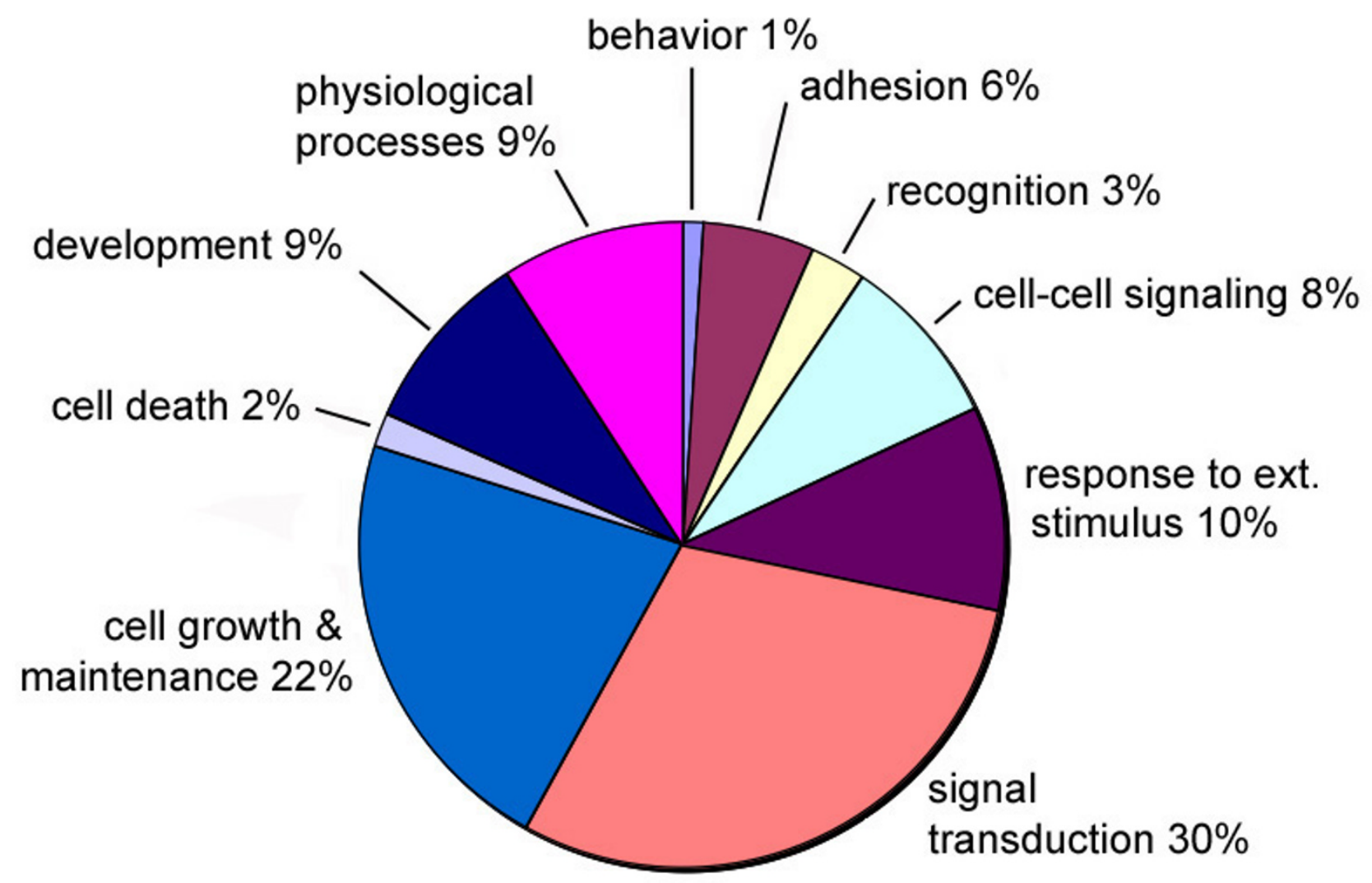

\section{Figure 1}

\section{Figure I}

Gene ontology of custom chip probes. The ontological classification of 3531 cell surface or secreted genes was extracted from the Gene Ontology at the third level. Genes lacking GO annotations at this level were derived from level 2.

other secreted and cell surface proteins. Finally, other putative secreted and transmembrane-encoding genes and exons were analyzed from hypothetical predictions from the UCSC Human Genome. Redundant genes were removed by a combination of blastn/blastp comparisons and manual curation, but many putative membraneencoding exons of potential proteins were included. A final tally of 3531 genes was composed of 1057 secreted genes, 1338 G-protein coupled receptor (GPCR) genes with the remainder classified as various integral membrane proteins and cell surface proteins. An ontological view of the custom chip's content is shown in Fig. 1. Finally, in consideration of potential global changes of a selected set of genes, numerous positive and negative controls were included in the array design; including genes characteristic of some tumors (e.g. the estrogen receptor for a subset of breast tumors) and many 'housekeeping' transcripts (e.g. $\beta$-actin) commonly used to normalize quantitative PCR studies. However, co-hybridizing all samples with a reference cDNA derived from a mixture of 10 human cell lines enabled 'normalization' with respect to feature, chip, and dye for the MANOVA analysis. This strategy minimizes the potential concern for a skewed normalization by a sub-selected gene population or possible differential behavior of the included 'housekeeping' genes in the xenograft tumors. 


\section{Identification of characteristic tumor-specific genes by all tumor data or individual tumor types by multivariate analysis of variation}

We performed several multivariate analyses of the microarray data to find characteristic tumorigenic genes. The MAANOVA tools [24] were chosen for their sensitivity and robustness in measuring differential expression versus previous T-test and log-ratio methods using thresholds for induction or suppression. This was particularly important in these studies that used a relatively complex design with on-chip and inter-chip probe replication, multiple tumor samples and tumor types, dye-swap and a common reference RNA sample for all hybridizations. Thus, this strategy helps avoid any systematic bias from using a chip containing probes for only secreted and cell surface genes. We developed a custom database [25] to allow dynamic re-grouping of data to facilitate multiple analytical models such as all tumor data or individual tumor types and their parental cell lines.

Initially, we identified the differentially expressed genes in all tumors relative to all parental cells regardless of tissue origin. Hence compared all the xenograft tumor data to all the parental cell line data without regard to tumor type. Similarly, both the tumor and parental cell line data were compared to the all reference cDNA hybridization data. These data were analyzed by both principal components analysis (PCA) and multivariate analysis of variance (MANOVA).

\section{Principal components analysis}

To visualize all tumor and parental cell data and assess overall quality, we subjected the entire dataset to principal components analysis. As shown in Fig. 2, a discrete segmentation of the data into 3 major aggregates corresponding to xenografts (circles), parental cell lines ("X's") and the universal reference cDNA (solid dots) can be identified. The third principal component shown by the vertical Y-axis provided the best separation between parental cell data and the xenograft tumor data, Fig. 2.

\section{Linear discriminant analysis}

In order to identify a profile characteristic of xenograft tumors where the combination of multiple genes might be more predictive than any single gene, we performed a linear discriminant analysis. Hence, we iteratively 'trimmed' versions of the third principal component since it had the highest correlation to sample type. The 'trimmed' list of coefficients were tested to determine their accuracy in assigning samples to either the tumor or cell line categories. This analysis retained 70 of the largest coefficients of the third principal component and represents a simple linear discriminant (LD) of 70 probes that corresponds to 54 genes. The profile of 70 probes fairly accurately distinguishes between the two sample types of parental cell lines and xenograft tumors, Fig. 3A. In 'leaveone-out' testing where each of the 99 samples was removed in separate analyses, this method generated a profile that was $79.8 \%$ accurate in predicting a xenograft tumor. The same method applied to 1000 label-permuted datasets never exceeded $65 \%$ accuracy with a median and minimum accuracy of $49 \%$ and $39.3 \%$ respectively. This suggests that the gene profile generated by our analysis can distinguish between the xenograft data and the cell line data in a verifiable manner.

\section{Ontological classification of genes identified by a linear discriminant}

The 54-gene profile derived from the linear discriminant (LD-p54) was distributed amongst numerous biological processes using the Gene Ontology classification terms, Table 1. Many genes were classified in multiple biological process categories as a result of their biological complexity; e.g. fibronectin (FN1) is classified into 8 biological processes including cell motility, response to stress, cell communication, response to external stimuli, extracellular matrix structural constituent, protein binding and glycosaminoglycan binding. Other genes are involved with cell adhesion or extracellular matrix, cellular growth or the regulation of cellular proliferation, various membrane proteins with known or inferred functions, transporters or channels, and proteases or protease inhibitors. A nonredundant ontological classification of the genes identified by the linear discriminant is shown with a graphical representation of their behavior across all tumor types, Fig 3B. Since the linear discriminant analysis uses a weighted sum, not all of the identified genes behaved consistently across all xenograft tumors; e.g. CD164 or COL4A1, Fig 3B.

\section{Analysis of variation of all xenograft data}

The expression data was also subjected to ANOVA using all xenograft and parental cell line data. In this analysis, the type of tumor or parental line was ignored. This analysis identified 156 probes representing 149 differentially regulated genes at the 99.9\% confidence level, Table 2 . The range of induction or suppression of this set of genes (ANOVA-p149) was 6-fold induction and 5-fold suppression. Twenty-nine of the 54 genes found by the above linear discriminant analysis were found in the list of 149 ANOVA-qualified probes. An ontological clustering of the ANOVA-p149 genes revealed patterns of proteases and protease inhibitors, cell-matrix adhesion genes, receptors, ion channels, various ligands including chemokines and interleukins, additional angiogenic genes and several genes of unknown function, Tables 3 and 4 show the major ontological groups. 


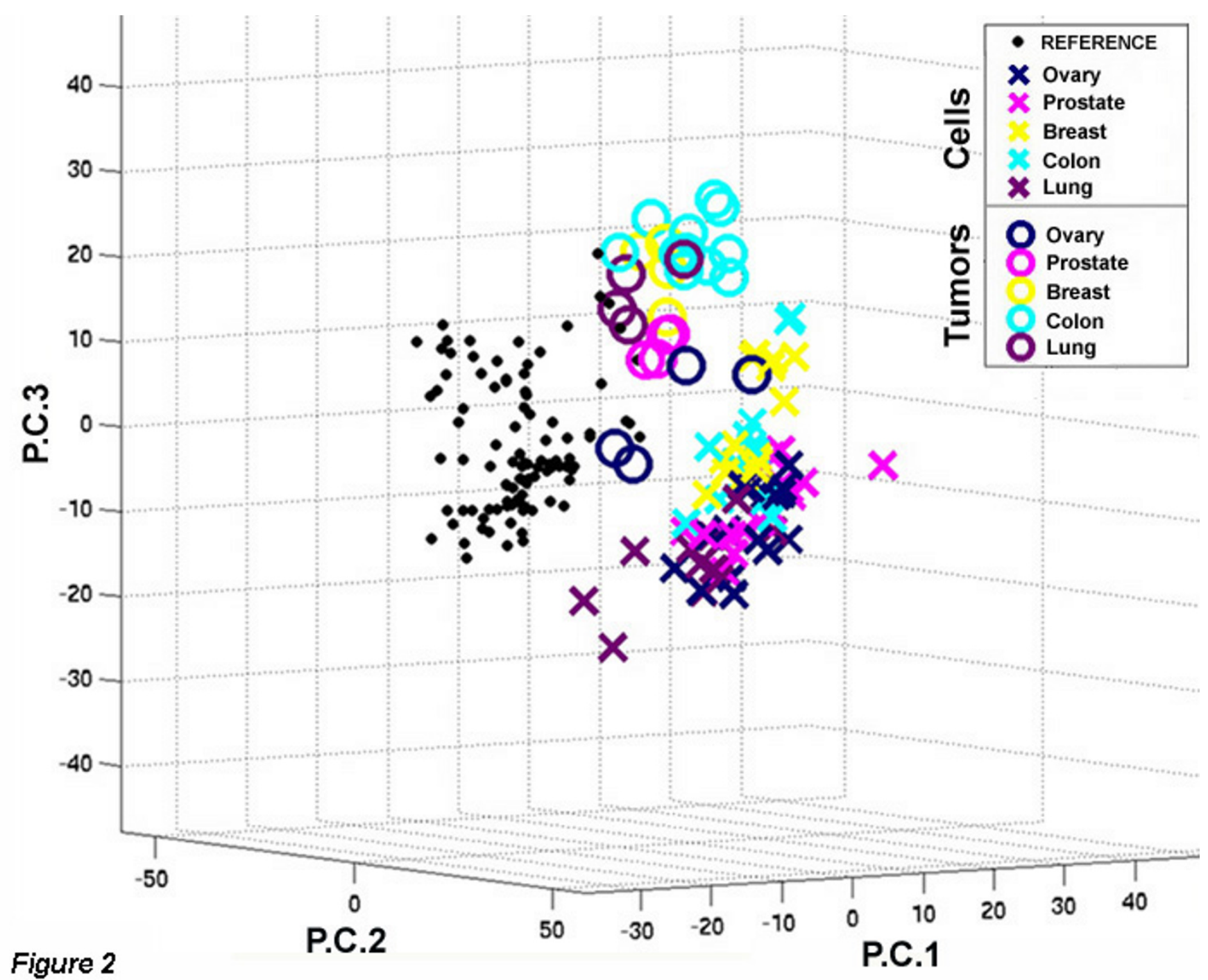

Figure 2

Principal components analysis of array data. The mean expression values of all samples from all arrays were analyzed by principal components analysis. The first 3 principal components of the analysis are shown from the best vantage point to show separation of the three classes. Open circles represent the parental cell lines, " $X$ " denotes the various xenograft tumors, and the small solid dots are the reference cDNA sample (derived from the Universal RNA) co-hybridized with all experimental samples. The cell lines corresponding to the various tissue sources of the parental cell lines were: Ovary, SKOV3; Prostate, PC3; Breast, MDA MB-23I; Colon, HCTII6; and Lung, A549.

Verification of selected genes by quantitative PCR analysis The differential expression of selected genes was confirmed by quantitative real-time PCR using the same RNA samples subjected to microarray hybridization. The vast majority of the genes tested by PCR validated the array analysis, Fig. 5. In some instances, discrepancies in foldinduction can be explained by methodological differences since the array data were all normalized to the co-hybridized universal-RNA sample, while the PCR data were nor- malized to a $\beta$-actin probe (data not shown). Differential expression of ANGPTL4, GP2, GNAO1, CCR4, FGF23, SPP1 and COL1A1 were qualitatively consistent in both the PCR and array analyses. However, two of the downregulated genes identified by the array analysis, both Gprotein coupled receptors, were found by PCR to be elevated, albeit with large variability; GPR10 was induced 281-fold SD = 469 and GPR110 induced 50-fold SD = 105. Of the two down-regulated genes examined by 
A

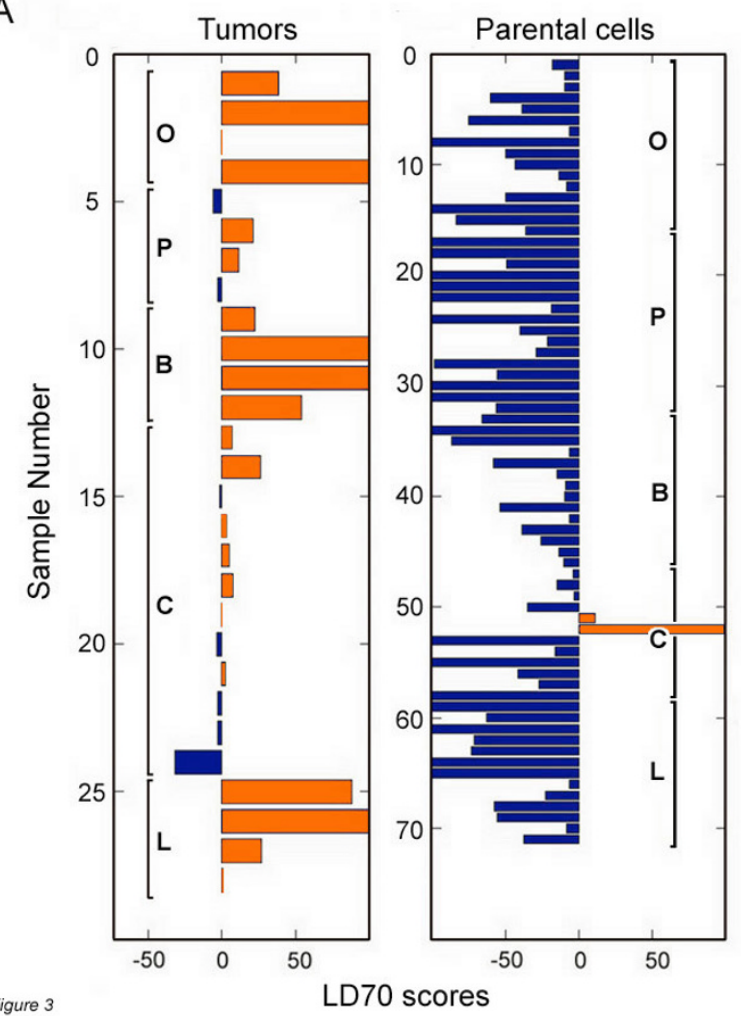

B

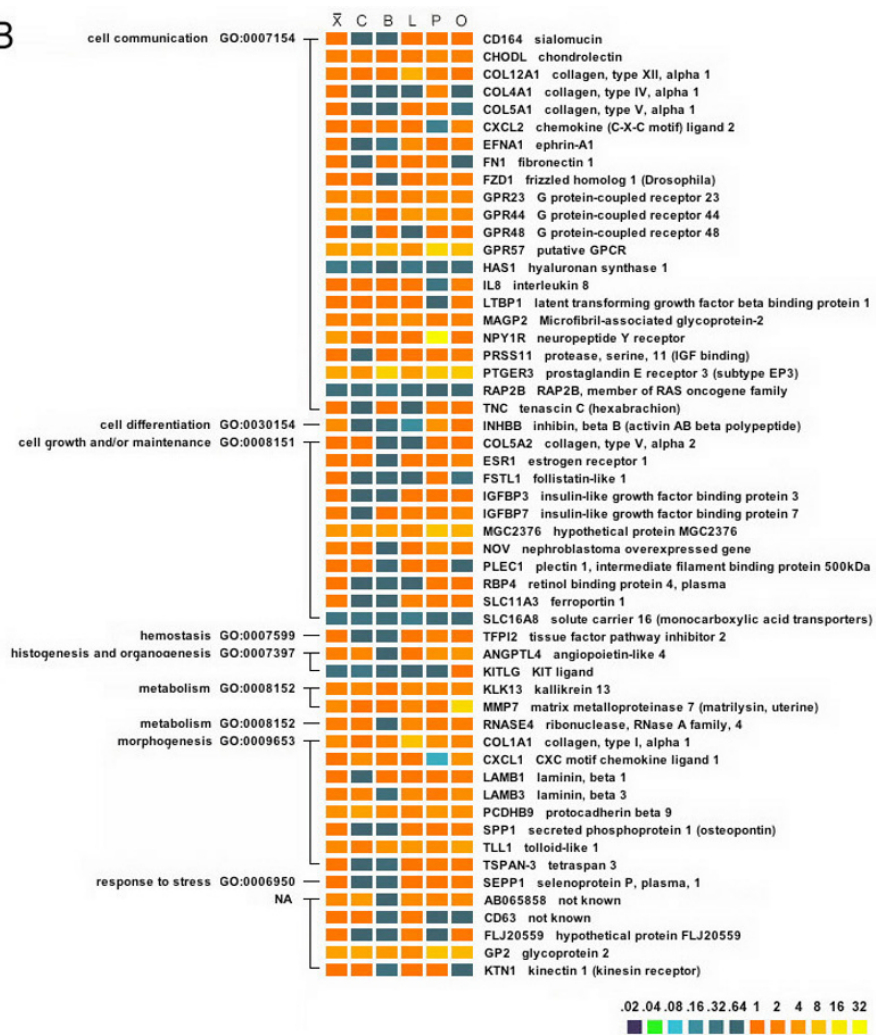

Figure 3

Genes identified by linear discriminant analysis. The top 70 PCA coefficients along the third principal component were selected. Panel A: Plot of linear discriminant profile of 70 probes that distinguish xenograft tumors from parental cell lines. Positive values in orange indicate "Xenograft tumor" while negative values in blue indicate "Parental Cell line". The y-axis shows either numbered tumor (left) or parental cell (right) samples and the $\mathbf{x}$-axis is an arbitrarily scaled output reflecting the accuracy in assigning a sample as a xenograft tumor or parental cell line. The numbered tumors were grouped according to tissue type as indicated by C for colon (HCTI I6), B for breast (MDA MB-23I), L for lung (A549), P for prostate (PC3) and O for ovary (SKOV-3). Panel B: Graphical representation of the LD-p54 genes expression profiles. For genes with multiple probes, the highest value is shown. Classified by a non-redundant filtering of the Gene Ontology biological process terms, the genes are shown with a color scale representing relative fold induction to all parental cell line data. The left-most color column designated by ' $X$ ' is the average ratio, while the remaining five columns correspond to Colon (HCTII6), Breast (MDA MB-23I), Lung (A549), Prostate (PC3) and Ovarian (SKOV-3) carcinoma xenografts respectively.

quantitative PCR, CD81 was consistent in both assays, while CD44 was measured by PCR as unchanged or minimally induced yet array analysis indicated $C D 44$ was suppressed. However, the aggregate 2-fold CD44 induction as measured by quantitative PCR is the threshold of what is considered significantly distinguishable from unchanged. Finally, while we did not perform PCR with species-specific probes for every gene present in the ANOVA-p149 list, we were able to confirm differential expression of several human genes from mouse genes such as the osteopontin genes, Fig. 5. While this analysis does not rule out the possibility of partial contamination of the array results by some weak cross-hybridization, to guard against this possibility we carefully designed probes to be species-spe- cific under the stringent hybridization conditions used in this study.

\section{ANOVA analysis of individual tumor types}

To accommodate the possibility that tumor type was an important contributor to differential gene behavior, we performed a third analysis by examining the intersection between the differential genes of each individual tumor type. For this restrictive analysis, we simply examined each tumor type relative to its parental cell line by ANOVA. Approximately 91-312 genes were differentially expressed at $99.9 \%$ confidence for each cell line: SKOV-3, 125 differential genes; MDA, 312 differential genes; HCT116, 124 differential genes; A549, 159 differential 
Table I: Gene ontology classification of 54 genes identified by a linear discriminant.

\begin{tabular}{|c|c|c|}
\hline GO & Process & Genes \\
\hline GO:0006928 & cell motility & HASI TSPAN-3 FNI IL8 \\
\hline GO:0006950 & response to stress & CXCL2 CXCLI SEPPI FNI SPPI IL8 \\
\hline GO:0007I54 & cell communication & $\begin{array}{l}\text { MAGP2 LTBPI PTGER3 COL4AI COLI2AI IGFBP3 GPR48 CXCL2 PCDHB9 COL5AI TNC } \\
\text { FZDI CDI64 CHODL CXCLI HASI LAMB3 GPR57 EFNAI FNI LAMBI SPPI GPR23 GPR44 } \\
\text { PRSSII RAP2B INHBB NPYIR ESRI IL8 KITLG }\end{array}$ \\
\hline GO:0007397 & histogenesis and organogenesis & KITLG \\
\hline GO:0007599 & hemostasis & TFPI2 \\
\hline GO:000763I & feeding behavior & NPYIR \\
\hline GO:0008I5I & cell growth and/or maintenance & $\begin{array}{l}\text { FSTLI NOV IGFBP3 RBP4 MGC2376 CDI } 64 \text { CXCLI TSPAN-3 SLCI IA3 SLCI6A8 PLECI } \\
\text { KTNI SPPI COL5A2 PRSSII INHBB IGFBP7 ESRI IL8 KITLG }\end{array}$ \\
\hline GO:0008I52 & metabolism & PTGER3 KLKI3 HASI SEPPI TLLI PRSSI I MMP7 INHBB RNASE4 ESR I \\
\hline GO:0008219 & cell death & PTGER3 SPPI \\
\hline GO:0009605 & response to external stimulus & RBP4 CXCL2 CDI64 CXCLI SEPPI FNI SPPI GPR44 INHBB IL8 \\
\hline GO:0009653 & morphogenesis & ANGPTL4 COLI2AI PCDHB9 CXCLI LAMB3 TSPAN-3 SPPI COLIAI TLLI INHBB IL8 \\
\hline GO:000979I & post-embryonic development & INHBB \\
\hline GO:0016265 & death & PTGER3 SPPI \\
\hline GO:0019058 & viral infectious cycle & IL8 \\
\hline GO:0030154 & cell differentiation & SPPI INHBB \\
\hline GO:0042698 & menstrual cycle & INHBB \\
\hline GO:0046849 & bone remodeling & SPPI \\
\hline GO:0046903 & secretion & INHBB \\
\hline NA & not known & CD63 FLJ20559 GP2 AB065858 \\
\hline
\end{tabular}

A level 3 annotation of the biological process Gene Ontology terms was applied to the list. Due to biological complexity, a gene can occur in more than one category.

genes; and PC3, 91 differential genes (data not shown). Twelve genes were found in common amongst these separately analyzed tumor types, ANGPLT4, COL1A1, epithelial membrane protein 3 (EMP3), GNAO1, glycoprotein 2 (GP2), GPR57, HAS1, HLAA, laminin beta 3 (LAMB3), PCDHB9, protease inhibitor 3 (PI3), and PTGER3, Table 2.

\section{Comparison of multiple analyses}

In a typical analysis of multivariate data, a particular method is often chosen as a filter for subsequent analyses. In this study, due to the high statistical reliability imparted by the high replicate probe count ( $\mathrm{n}=18$ to 30 ) enabled by the custom array design, we chose to compare the results of 3 different approaches to the intact dataset 
Table 2: Differentially expressed genes from three analyses. ANOVA of xenograft data vs parental cell lines found I49 differential genes (designated ' Ap'), Linear discriminant analysis found 54 genes (designated 'LD') and ANOVA of individual xenograft tumors yielded a consensus of 12 genes (designated ' $A i$ '). For each gene, its presence is denoted by ' $\mathrm{I}$ ' and its absence noted by ' 0 '. The maximum MANOVA Pvalue is reported along with the aggregate ratio (designated by ' $R$ '). For genes with multiple independent probes, the probe reporting the maximum Pvalue is shown. Seven genes common to all three lists are in bold text.

\begin{tabular}{|c|c|c|c|c|c|}
\hline Ap & LD & $\mathrm{Ai}$ & Gene & Pval & $\mathrm{R}$ \\
\hline I & I & I & LAMB3 & 0.001 & 1.9 \\
\hline $\mathbf{I}$ & I & $\mathbf{I}$ & ANGPTL4 & 0.001 & 2.1 \\
\hline $\mathbf{I}$ & I & I & COLIAI & 0.001 & 3.6 \\
\hline I & I & I & PCDHB9 & 0.001 & 4.0 \\
\hline I & I & $\mathbf{I}$ & GPR57 & 0.001 & 5.7 \\
\hline I & I & I & GP2 & 0.001 & 5.7 \\
\hline I & I & I & PTGER3 & 0.001 & 6.4 \\
\hline 1 & I & 0 & KITLG & 0.001 & 0.4 \\
\hline 1 & 1 & 0 & RAP2B & 0.001 & 0.4 \\
\hline I & I & 0 & COL5AI & 0.237 & 1.0 \\
\hline I & I & 0 & SEPPI & 0.054 & 1.0 \\
\hline I & I & 0 & CXCLI & 0.3 & 1.1 \\
\hline I & 1 & 0 & TNC & 0.001 & 1.3 \\
\hline 1 & I & 0 & LTBPI & 0.009 & 1.3 \\
\hline I & 1 & 0 & PRSSII & 0.001 & 1.3 \\
\hline I & I & 0 & FNI & 0.008 & 1.4 \\
\hline I & I & 0 & FZDI & 0.019 & 1.4 \\
\hline I & I & 0 & SPPI & 1 & 1.5 \\
\hline 1 & 1 & 0 & IGFBP7 & 0.001 & 1.7 \\
\hline I & 1 & 0 & RNASE4 & 0.008 & 1.9 \\
\hline I & I & 0 & CHODL & 0.003 & 2.1 \\
\hline 1 & I & 0 & NOV & 0.003 & 2.2 \\
\hline I & I & 0 & COLI2AI & 0.001 & 2.2 \\
\hline I & I & 0 & MAGP2 & 0.001 & 2.6 \\
\hline I & I & 0 & GPR23 & 0.574 & 3.0 \\
\hline 1 & 1 & 0 & TLLI & 0.001 & 3.2 \\
\hline 1 & I & 0 & GPR44 & 0.069 & 3.6 \\
\hline I & I & 0 & MGC2376 & 0.001 & 4.7 \\
\hline 1 & I & 0 & NPYIR & 0.183 & 5.2 \\
\hline I & 0 & $\mathrm{I}$ & EMP3 & 0.004 & 0.5 \\
\hline I & 0 & 1 & HLA-A & 0.001 & 0.6 \\
\hline 1 & 0 & 1 & GNAOI & 0.001 & 2.5 \\
\hline I & 0 & 0 & CCR5 & 0.001 & 0.2 \\
\hline 1 & 0 & 0 & C20orf52 & 0.001 & 0.4 \\
\hline I & 0 & 0 & SORCS3 & 0.001 & 0.4 \\
\hline I & 0 & 0 & PF4 & 0.005 & 0.4 \\
\hline I & 0 & 0 & SPINK2 & 0.001 & 0.4 \\
\hline I & 0 & 0 & IGSF6 & 0.008 & 0.4 \\
\hline 1 & 0 & 0 & GPRIIO & 0.001 & 0.5 \\
\hline I & 0 & 0 & ORIJ5 & 0.001 & 0.5 \\
\hline I & 0 & 0 & BGLAP & 0.001 & 0.5 \\
\hline I & 0 & 0 & GALR2 & 0.001 & 0.5 \\
\hline I & 0 & 0 & $\mathrm{HCN} 2$ & 0.001 & 0.5 \\
\hline 1 & 0 & 0 & CD8I & 0.001 & 0.5 \\
\hline I & 0 & 0 & OGFR & 0.001 & 0.5 \\
\hline 1 & 0 & 0 & GPR6 & 0.001 & 0.5 \\
\hline I & 0 & 0 & OMP & 0.001 & 0.5 \\
\hline I & 0 & 0 & CMAI & 0.001 & 0.5 \\
\hline 1 & 0 & 0 & DKFZP564DO & 0.001 & 0.6 \\
\hline I & 0 & 0 & CHRMI & 0.001 & 0.6 \\
\hline I & 0 & 0 & PYY & 0.001 & 0.6 \\
\hline I & 0 & 0 & FGFI9 & 0.004 & 0.6 \\
\hline I & 0 & 0 & AGTR2 & 0.047 & 0.6 \\
\hline I & 0 & 0 & SSTR3 & 0.001 & 0.6 \\
\hline I & 0 & 0 & TMPO & 0.001 & 0.6 \\
\hline 1 & 0 & 0 & TAS2RI6 & 0.003 & 0.6 \\
\hline
\end{tabular}


Table 2: Differentially expressed genes from three analyses. ANOVA of xenograft data vs parental cell lines found I49 differential genes (designated ' Ap'), Linear discriminant analysis found 54 genes (designated 'LD') and ANOVA of individual xenograft tumors yielded a consensus of 12 genes (designated ' $A i$ '). For each gene, its presence is denoted by ' $\mathrm{I}$ ' and its absence noted by ' 0 '. The maximum MANOVA Pvalue is reported along with the aggregate ratio (designated by ' $R$ '). For genes with multiple independent probes, the probe reporting the maximum Pvalue is shown. Seven genes common to all three lists are in bold text. (Continued)

\begin{tabular}{|c|c|c|c|c|c|}
\hline$T$ & 0 & 0 & ADORA2B & 0.003 & 0.6 \\
\hline I & 0 & 0 & GPRIO & 0.001 & 0.6 \\
\hline I & 0 & 0 & ADCYAPIRI & 0.001 & 0.6 \\
\hline I & 0 & 0 & ORIFIO & 0.001 & 0.6 \\
\hline I & 0 & 0 & HDGF & 0.001 & 0.6 \\
\hline I & 0 & 0 & CDI5I & 0.001 & 0.6 \\
\hline I & 0 & 0 & PDAPI & 0.001 & 0.7 \\
\hline I & 0 & 0 & AIBG & 0.001 & 0.7 \\
\hline I & 0 & 0 & LIPF & 0.001 & 0.7 \\
\hline I & 0 & 0 & PBEF & 0.001 & 0.7 \\
\hline I & 0 & 0 & ART-4 & 0.034 & 0.7 \\
\hline I & 0 & 0 & CIQTNF3 & 0.029 & 0.7 \\
\hline I & 0 & 0 & SLC39A4 & 0.022 & 0.7 \\
\hline 1 & 0 & 0 & IFNGR2 & 0.001 & 0.8 \\
\hline I & 0 & 0 & ENT3 & 0.001 & 0.8 \\
\hline I & 0 & 0 & SERPINCI & 0.001 & 0.8 \\
\hline I & 0 & 0 & NRPI & 0.006 & 0.8 \\
\hline I & 0 & 0 & CACNAIH & 0.011 & 0.8 \\
\hline I & 0 & 0 & CD44 & 0.001 & 0.8 \\
\hline I & 0 & 0 & STC2 & 0.018 & 0.8 \\
\hline I & 0 & 0 & DLKI & 0.064 & 0.8 \\
\hline I & 0 & 0 & $\mathrm{~F} 2 \mathrm{R}$ & 0.388 & 0.8 \\
\hline I & 0 & 0 & EMP2 & 0.001 & 0.8 \\
\hline I & 0 & 0 & HBEI & 0.003 & 0.8 \\
\hline I & 0 & 0 & BSG & 0.003 & 0.8 \\
\hline I & 0 & 0 & GPR80 & 0.001 & 0.8 \\
\hline I & 0 & 0 & APOB48R & 0.016 & 0.8 \\
\hline I & 0 & 0 & AMELY & 0.001 & 0.8 \\
\hline I & 0 & 0 & IL26 & 0.006 & 0.8 \\
\hline I & 0 & 0 & TRPM5 & 0.001 & 0.8 \\
\hline I & 0 & 0 & ENSA & 0.001 & 0.8 \\
\hline I & 0 & 0 & ORIFI & 0.001 & 0.8 \\
\hline 1 & 0 & 0 & GP3ST & 0.001 & 0.8 \\
\hline I & 0 & 0 & BDNF & 0.001 & 0.9 \\
\hline I & 0 & 0 & PLXN3 & 0.005 & 0.9 \\
\hline I & 0 & 0 & APMCFI & 0.134 & 0.9 \\
\hline I & 0 & 0 & SCAMPI & 0.001 & 0.9 \\
\hline 1 & 0 & 0 & PALMD & 0.001 & 0.9 \\
\hline I & 0 & 0 & MMP8 & 0.02 & 0.9 \\
\hline I & 0 & 0 & MFAP3 & 0.004 & 0.9 \\
\hline I & 0 & 0 & SPAGII & 0.001 & 0.9 \\
\hline I & 0 & 0 & $A 2 M$ & 0.031 & 0.9 \\
\hline I & 0 & 0 & NET-2 & 0.092 & 0.9 \\
\hline I & 0 & 0 & CXCLII & 0.001 & 1.0 \\
\hline I & 0 & 0 & KLRBI & 0.003 & 1.0 \\
\hline I & 0 & 0 & $\mathrm{TF}$ & 0.988 & 1.0 \\
\hline I & 0 & 0 & COLI4AI & 0.001 & 1.0 \\
\hline I & 0 & 0 & IL7 & 0.002 & 1.1 \\
\hline 1 & 0 & 0 & COL9AI & 0.001 & 1.1 \\
\hline I & 0 & 0 & CCR4 & 0.001 & 1.1 \\
\hline I & 0 & 0 & FPRI & 0.034 & 1.1 \\
\hline I & 0 & 0 & FAP & 0.001 & 1.2 \\
\hline I & 0 & 0 & OPCML & 0.001 & 1.2 \\
\hline I & 0 & 0 & GPRI45 & 0.001 & 1.2 \\
\hline 1 & 0 & 0 & GFRA3 & 0.001 & 1.2 \\
\hline 1 & 0 & 0 & EDN3 & 0.001 & 1.2 \\
\hline I & 0 & 0 & ILI $2 B$ & 0.043 & 1.3 \\
\hline I & 0 & 0 & CXCR4 & 0.026 & 1.3 \\
\hline
\end{tabular}


Table 2: Differentially expressed genes from three analyses. ANOVA of xenograft data vs parental cell lines found I49 differential genes (designated ' Ap'), Linear discriminant analysis found 54 genes (designated 'LD') and ANOVA of individual xenograft tumors yielded a consensus of 12 genes (designated ' $A i$ '). For each gene, its presence is denoted by ' $\mathrm{I}$ ' and its absence noted by ' 0 '. The maximum MANOVA Pvalue is reported along with the aggregate ratio (designated by ' $R$ '). For genes with multiple independent probes, the probe reporting the maximum Pvalue is shown. Seven genes common to all three lists are in bold text. (Continued)

\begin{tabular}{|c|c|c|c|c|c|}
\hline$T$ & 0 & 0 & PCSK5 & 0.427 & 1.3 \\
\hline I & 0 & 0 & NID2 & 0.168 & 1.3 \\
\hline I & 0 & 0 & ITGA4 & 0.73 & 1.3 \\
\hline I & 0 & 0 & KIAAI 870 & 0.016 & 1.3 \\
\hline I & 0 & 0 & FBLN5 & 0.001 & 1.4 \\
\hline I & 0 & 0 & TRPV2 & 0.001 & 1.4 \\
\hline I & 0 & 0 & FGF23 & 0.119 & 1.4 \\
\hline I & 0 & 0 & TEM5 & 0.001 & 1.4 \\
\hline I & 0 & 0 & CRI & 0.008 & 1.4 \\
\hline I & 0 & 0 & GPA33 & 0.001 & 1.4 \\
\hline I & 0 & 0 & CLCA4 & 0.001 & 1.4 \\
\hline I & 0 & 0 & TIMP3 & 0.006 & 1.4 \\
\hline I & 0 & 0 & MMPIO & 0.001 & 1.4 \\
\hline I & 0 & 0 & FUT8 & 0.197 & 1.4 \\
\hline I & 0 & 0 & FIBL-6 & 0.001 & 1.4 \\
\hline I & 0 & 0 & VIRLI & 0.001 & 1.5 \\
\hline I & 0 & 0 & $\mathrm{~EB} \mid 2$ & 0.003 & 1.5 \\
\hline I & 0 & 0 & ADAM28 & 0.001 & 1.5 \\
\hline I & 0 & 0 & GPLDI & 0.008 & 1.5 \\
\hline i & 0 & 0 & $\mathrm{CP}$ & 0.003 & 1.5 \\
\hline I & 0 & 0 & EPHA3 & 0.003 & 1.5 \\
\hline I & 0 & 0 & KLKII & 0.001 & 1.6 \\
\hline I & 0 & 0 & OR7AI7 & 0.001 & 1.6 \\
\hline I & 0 & 0 & IFI27 & 0.001 & 1.7 \\
\hline I & 0 & 0 & RNASE6 & 0.003 & 1.7 \\
\hline I & 0 & 0 & SELPLG & 0.001 & 1.7 \\
\hline 1 & 0 & 0 & CST7 & 0.092 & 1.7 \\
\hline I & 0 & 0 & LEC3 & 0.001 & 1.7 \\
\hline I & 0 & 0 & TSHR & 0.001 & 2.1 \\
\hline I & 0 & 0 & $M C 2 R$ & 0.001 & 2.1 \\
\hline i & 0 & 0 & SV2 & 0.001 & 2.1 \\
\hline I & 0 & 0 & SERPINA4 & 0.001 & 2.1 \\
\hline I & 0 & 0 & ANGPT2 & 0.003 & 2.2 \\
\hline i & 0 & 0 & LOC84664 & 0.008 & 2.3 \\
\hline I & 0 & 0 & RNASEI & 0.001 & 2.9 \\
\hline 0 & 1 & I & HASI & 1 & 0.3 \\
\hline 0 & 1 & 0 & SLCI6A8 & I & 0.4 \\
\hline 0 & I & 0 & CDI64 & 1 & 1.0 \\
\hline 0 & 1 & 0 & FSTLI & 1 & 1.0 \\
\hline 0 & 1 & 0 & IL8 & 1 & 1.0 \\
\hline 0 & I & 0 & KTNI & 1 & 1.0 \\
\hline 0 & 1 & 0 & RBP4 & I & 1.1 \\
\hline 0 & 1 & 0 & COL5A2 & I & 1.1 \\
\hline 0 & 1 & 0 & TSPAN-3 & 1 & I.I \\
\hline 0 & I & 0 & CD63 & 1 & 1.1 \\
\hline 0 & 1 & 0 & IGFBP3 & I & I.I \\
\hline 0 & 1 & 0 & PLECI & I & 1.1 \\
\hline 0 & 1 & 0 & CXCL2 & I & 1.2 \\
\hline 0 & 1 & 0 & GPR48 & 1 & 1.2 \\
\hline 0 & 1 & 0 & FLJ20559 & 1 & 1.2 \\
\hline 0 & 1 & 0 & LAMBI & 1 & 1.3 \\
\hline 0 & 1 & 0 & COL4AI & 0.994 & 1.3 \\
\hline
\end{tabular}




\begin{tabular}{|c|c|c|c|c|c|}
\hline 0 & 1 & 0 & TFPI2 & 1 & 1.4 \\
\hline 0 & 1 & 0 & ESRI & 0.996 & 1.5 \\
\hline 0 & 1 & 0 & SLCIIA3 & 0.999 & 1.6 \\
\hline 0 & 1 & 0 & EFNAI & 1 & 1.6 \\
\hline 0 & 1 & 0 & KLKI3 & 1 & 2.5 \\
\hline 0 & 1 & 0 & AB065858 & 1 & 3.1 \\
\hline 0 & 1 & 0 & MMP7 & 0.987 & 3.4 \\
\hline 0 & 1 & 0 & INHBB & 1 & 3.5 \\
\hline 0 & 0 & I & $\mathrm{PI3}$ & 1 & 0.4 \\
\hline
\end{tabular}

but modeled as either all data or individual tumor types. An estimate of the statistical significance of the overlap in differentially expressed genes common to the three analytical methods gave a Pvalue of $<1 \times 10^{-6}$ as described in the legend to Fig. 6 . As shown in Fig. 6, seven of the twelve differential genes found amongst individual tumor ANOVA analyses were common to the linear discriminant gene profile (LD-p54): ANGPLT4, COL1A1, GP2, GPR57, LAMB3, PCDHB9, and PTGER3.

Real-time PCR analysis generally confirmed either induction or suppression in multiple tumor samples but with higher induction ratios; e.g. from Fig. 5, the level of ANGPTL4 was measured by PCR as induced 19 to 453 fold with a average fold induction of 185 SD $=170$ for 10 tumors (2 of each type). The aggregate induction of ANGPTL4 in the array analysis was 2.09 fold (Pcorr $<2$ e9). Similarly, COL1A1 was measured by PCR as induced in most tumors with an average 9.8 -fold $(S D=9.1)$ versus a 3.64-fold induction found by microarray analysis. Finally, in ovarian and prostate tumors, angiopoietin 2 (ANGPT2) measured by PCR was elevated 6-fold (data not shown) versus the 2.2-fold induction found by microarray analysis.

\section{Discussion}

Overall, the pathways represented by the differential genes in xenograft tumors support a model for late angiogenic expression patterns. In light of the collection of xenografts after 28-29 days post-implantation, is not surprising to find patterns of differential gene expression that reflect a portion of the tumorigenic process rather than a preponderance of early transforming events. This premise is largely supported by the abundance of extracellular matrix, cell adhesion and angiopoetic genes common to the three analyses.
Ten of the 12 induced genes identified by the ANOVA of xenografts were either well-characterized functions or biological roles, particularly angiogenesis (ANGPTL4), morphogenesis (LAMB3, COL1A1, PCDHB9, or cellular mobility or communication (HAS1, PTGER3, PCDHB9, and $L A M B 3$ ). The role of extracellular matrix genes in tumor growth has been previously noted $[7,8]$. Interestingly, five of the extracellular matrix genes from the linear discriminant analysis were collagens (COL1A1, COL4A1, COL5A1, COL5A2 and COL12A1) and four of these collagens (COL1A1, COL4A1, COL5A1, and COL5A2) have been previously found induced in primary renal cell carcinomas $(4.8,5.0,3.25$ and 3.6 fold respectively [26]. COL1A1 has also been found induced in most breast carcinomas $[27,28]$, and a subset of ovarian and colon carcinomas [28].

Consistent with an overall pattern of late-stage angiogenesis in xenograft tumors, ANGPTL4 was found consistently induced relative to the parental cell lines by all analyses. ANGPTL4 originally was described as an induced target of peroxisome proliferator-activated receptor gamma that is involved in glucose homeostasis and differentiation of adipose tissue [29]. Subsequently ANGPTL4 was shown to possess angiogenic activity in the chick allochorionic migration assay [30]. More recently, ANGPTL4 was shown to bind and inhibit lipoprotein lipase [31], a function consistent with the cachexia induced by tumors, where a reduction of fatty acid incorporation into fat cells serves the energy needs of the tumor rather than the host. ANGPTL4's angiogenic action has been reported to be independent of VEGF in a renal carcinoma model [30]. Similarly to previous observations of induced angiopoietins in primary renal cell carcinomas (ANGPT2 8.18-fold induced and ANGPTL4 18-32-fold induced [26], we found both ANGPTL4 induction (2.09 
Table 3: Biological process classification of 175 genes derived from three analyses. The 149 genes derived from the ANOVA analysis of xenograft versus parental cell line data, the 54 genes identified by the linear discriminant analysis and the 12 genes derived from the intersect of ANOVA of individual tumors are shown. Gene Ontology terms were extracted at level 3 for the Unigene gene names. Not shown are genes multiply annotated into additional singular categories or genes absent from the Gene Ontology. Percentages were calculated from a total of 317 classifications into 3I Biological Process terms.

\begin{tabular}{|c|c|c|c|}
\hline GO & Process & $\%$ & Genes \\
\hline GO:0007I54 & cell communication & $26.8 \%$ & $\begin{array}{c}\text { HDGF PTGER3 CD44 TAS2R I6 GALR2 IGFBP3 COL5AI ORIFI } \\
\text { SORCS3 FZDI LAMB3 SELPLG GFRA3 IL26 CXCR4 PDAPI SSTR3 } \\
\text { ENSA CDI5I COL9AI OPCML GPRI45 GPR44 EPHA3 TNC GPR80 } \\
\text { HASI BGLAP EFNAI EBI2 EDN3 TSHR F2R PRSSII NRPI OMP } \\
\text { MC2R INHBB OR7AI7 IL8 AGTR2 GPR48 CHODL CXCLI OR IFI0 } \\
\text { CHRMI GPRI0 GPR57 NID2 GPR6 LAMBI CCR5 SPPI ADCYAPIRI } \\
\text { CXCLIII PCSK5 GPR23 RAP2B IFNGR2 IL7 COLI2AI PYY CXCL2 } \\
\text { PCDHB9 GPRIII0 CDI64 PBEF KLRBI FNI BSG IGSF6 FBLN5 STC2 } \\
\text { ANGPT2 ADORA2B PF4 ILI } 2 \text { 2B FPRI GPLDI CCR4 NPYIR ESRI } \\
\text { GNAOI ITGA4 KITLG }\end{array}$ \\
\hline GO:0008I5I & cell growth and/or maintenance & $1.55 \%$ & $\begin{array}{c}\text { HDGF IGFBP3 SORCS3 TSPAN-3 CXCR4 PDAPI SSTR3 ENSA } \\
\text { TRPV2 SLC39A4 TF EMP3 HBEI CACNAIH TSHR F2R COL5A2 } \\
\text { PRSSII NRPI INHBB CLCA4 IGFBP7 IL8 RBP4 MGC2376 CXCLI } \\
\text { CHRMI A2M CP CD8I CCR5 KTNI SPPI SCAMPI OGFR IL7 TRPM5 } \\
\text { NOV PYY CDI64 PBEF SLCI6A8 PLECI ANGPT2 HCN2 ILI I B EMP2 } \\
\text { ESRI KITLG }\end{array}$ \\
\hline GO:0009605 & response to external stimulus & $12.6 \%$ & $\begin{array}{l}\text { TAS2RI6 ORIFI IL26 CXCR4 ENSA TRPV2 GPR44 EBI2 EDN3 F2R } \\
\text { OMP RNASE6 INHBB OR7A I7 IL8 HLA-A RBP4 CXCLI TIMP3 SEPPI } \\
\text { CD8I CCR5 SPPI CXCLII IFNGR2 IL7 CST7 CXCL2 CDI64 CRI } \\
\text { KLRBI FNI IGSF6 STC2 ADORA2B PF4 ILI2B FPRI CCR4 IFI27 }\end{array}$ \\
\hline GO:0008152 & metabolism & $7.9 \%$ & $\begin{array}{l}\text { PTGER3 LIPF MMP7 EPHA3 KLKII HASI CMAI F2R MMPI0 FAP } \\
\text { PRSSII RNASE6 INHBB MMP8 CHRMI SEPPI CD8I PCSK5 RNASE4 } \\
\text { KLKI } 3 \text { ADAM28 FIBL-6 TLLI ILI2B ESRI }\end{array}$ \\
\hline GO:0009653 & morphogenesis & $7.9 \%$ & $\begin{array}{l}\text { BDNF LAMB3 TSPAN-3 GFRA3 CXCR4 CACNAIH BGLAP F2R } \\
\text { NRPI INHBB IL8 AMELY CXCLI CHRMI CCR5 SPPI COLIAI } \\
\text { COLI I AI PCDHB9 FGFI9 ANGPT2 TLLI PF4 ILI } 2 B \text { GNAOI }\end{array}$ \\
\hline GO:0006950 & response to stress & $6.0 \%$ & $\begin{array}{l}\text { IL26 CXCR4 F2R IL8 CXCLI SEPPI CCR5 SPPI CXCLII IFNGR2 IL7 } \\
\text { CXCL2 CRI KLRBI FNI ADORA2B ILI IB FPR I CCR4 }\end{array}$ \\
\hline GO:0006928 & cell motility & $3.5 \%$ & $\begin{array}{l}\text { GALR2 TSPAN-3 HASI CACNAIH F2R NRPI IL8 PYY FNI FPRI } \\
\text { GNAOI }\end{array}$ \\
\hline GO:0008219 & cell death & $2.5 \%$ & PTGER3 CXCR4 SSTR3 EMP3 F2R AGTR2 SPPI EMP2 \\
\hline GO:0016265 & death & $2.5 \%$ & PTGER3 CXCR4 SSTR3 EMP3 F2R AGTR2 SPPI EMP2 \\
\hline GO:0030154 & cell differentiation & $1.9 \%$ & BGLAP INHBB SPPI FGF23 PF4 ILI 2B \\
\hline GO:0007397 & histogenesis and organogenesis & $1.6 \%$ & CXCR4 COL9AI NRPI IL7 KITLG \\
\hline GO:0007599 & hemostasis & $1.3 \%$ & SERPINCI TFPI2 F2R PF4 \\
\hline GO:0000003 & reproduction & $0.9 \%$ & SPAGII ADCYAPIRI ADAM28 \\
\hline GO:000763I & feeding behavior & $0.9 \%$ & GALR2 PYY NPYIR \\
\hline GO:0009405 & pathogenesis & $0.9 \%$ & CXCR4 EDN3 TSHR \\
\hline GO:00080I5 & circulation & $0.9 \%$ & CACNAIH EDN3 AGTR2 \\
\hline GO:0046849 & bone remodeling & $0.9 \%$ & BGLAP AMELY SPPI \\
\hline GO:0007586 & digestion & $0.6 \%$ & GALR2 PYY \\
\hline GO:0019098 & reproductive behavior & $0.3 \%$ & $\mathrm{PI} 3$ \\
\hline GO:0030198 & extracellular matrix organization and biogenesis & $0.3 \%$ & COLI4AI \\
\hline
\end{tabular}

fold, Pcorr < 2e-9), and ANGPT2 induction (2.23-fold Pcorr <.005).

\section{Other post-VEGF angiogenic pathways}

The role of other elevated angiogenic genes downstream of VEGF bears discussion. The induction of the prostaglandin E receptor 3 (PTGER3- 6.4-fold, Pcorr <.001) is of interest since prostaglandins can induce VEGFA production $[32,33]$ via a hypoxia-induced pathway [34]. Coinci- dent with these observations, IGFBP7 which was differential by ANOVA and linear discriminant analysis, modulates IGF mitogenic activity [35]. IGFBP7 also stimulates prostacyclin synthesis [36] perhaps to take advantage of our observed 6-fold increased PTGER3 expression. Similarly, a human-specific probe for TEM5, a marker of tumor endothelial angiogenesis [37], was also found mildly increased $(1.37$-fold Pcorr $<.001)$ possibly as a result of vasculogenic mimicry $[14,38]$. 
Table 4: Molecular function classification of 175 genes derived from three analyses. As in Table 3, the gene names from three analyses were annotated according to the Gene Ontology Molecular Function categories. Not shown are genes multiply annotated into additional singular categories or genes absent from the Gene Ontology. Percentages were calculated from a total of $25 \mathrm{I}$ gene classifications into 52 Molecular Function terms.

\begin{tabular}{|c|c|c|c|}
\hline GO & Function & $\%$ & Genes \\
\hline GO:0004872 & receptor activity & $20.3 \%$ & $\begin{array}{l}\text { PTGER3 CD44 TAS2RI6 GALR2 ORIFI SORCS3 FZDI GFRA3 CXCR4 } \\
\text { APOB48R SSTR3 OPCML TRPV2 GPR I45 GPR44 EPHA3 GPA33 TNC } \\
\text { GPR80 EBI2 TSHR F2R NRPI MC2R OR7AI7 AGTR2 HLA-A GPR48 } \\
\text { ORIFI0 CHRMI GPRI0 GPR57 GPR6 CCR5 ADCYAPIRI GPR23 IFNGR2 } \\
\text { OGFR APMCFI GPRII0 CRI KLRBI IGSF6 ADORA2B ILI 2B GPLDI FPRI } \\
\text { CCR4 NPYIR ESRI ITGA4 }\end{array}$ \\
\hline GO:0005I02 & receptor binding & $10.8 \%$ & $\begin{array}{l}\text { HDGF BDNF SELPLG GFRA3 IL26 ENSA EFNAI EDN3 F2R INHBB IL8 } \\
\text { CXCLI SPPI CXCLII IL7 NOV PYY CXCL2 FGF23 PBEF FBLN5 FGFI9 } \\
\text { STC2 ANGPT2 PF4 ILI } 2 \text { B KITLG }\end{array}$ \\
\hline GO:0016787 & hydrolase activity & $7.6 \%$ & $\begin{array}{l}\text { RNASEI LIPF MMP7 KLK I I CMA I MMPI0 FAP PRSSI I RNASE6 MMP8 } \\
\text { PCSK5 RAP2B RNASE4 KLKI } 3 \text { ADAM } 28 \text { FIBL-6 TLLI GPLDI GNAOI }\end{array}$ \\
\hline GO:00055I5 & protein binding & $7.6 \%$ & $\begin{array}{l}\text { CD44 TMPO IGFBP3 CXCR4 LTBPI PRSSII INHBB IGFBP7 PI3 MGC2376 } \\
\text { A2M NID2 CCR5 IFNGR2 SERPINA4 NOV PLECI FNI CCR4 }\end{array}$ \\
\hline GO:0046872 & metal ion binding & $6.0 \%$ & $\begin{array}{l}\text { FSTLI MMP7 TF CACNAIH BGLAP MMPI0 LTBPI MMP8 CP NID2 } \\
\text { PCDHB9 ADAM28 FIBL-6 FBLN5 TLLI }\end{array}$ \\
\hline GO:0042277 & peptide binding & $6.0 \%$ & $\begin{array}{l}\text { GALR2 SORCS3 CXCR4 SSTR3 OPCML GPR44 F2R MC2R AGTR2 GPRI0 } \\
\text { CCR5 OGFR FPRI CCR4 NPYIR }\end{array}$ \\
\hline GO:000520I & extracellular matrix structural constituent & $4.8 \%$ & $\begin{array}{l}\text { COL5AI COL4AI COL9AI COLI4AI MAGP2 TFPI2 COL5A2 AMELY } \\
\text { COLIAI COLI2AI FNI MFAP3 }\end{array}$ \\
\hline GO:0004857 & enzyme inhibitor activity & $3.6 \%$ & SPINK2 SERPINCI TFPI2 PI3 AGTR2 A2M TIMP3 SERPINA4 CST7 \\
\hline GO:0015267 & channel/pore class transporter activity & $2.8 \%$ & TRPV2 CACNAIH CLCA4 MGC2376 CHRMI TRPM5 HCN2 \\
\hline GO:0005539 & glycosaminoglycan binding & $2.8 \%$ & HDGF FSTLI CD44 COL5AI SERPINCI FNI PF4 \\
\hline GO:0003676 & nucleic acid binding & $2.4 \%$ & TMPO RNASEI APOB48R RNASE6 RNASE4 ESRI \\
\hline GO:0000I66 & nucleotide binding & $2.4 \%$ & EPHA3 FLJ20559 RAP2B APMCFI HCN2 GNAOI \\
\hline GO:0016740 & transferase activity & $2.4 \%$ & EPHA3 HASI GP3ST FLJ20559 NRPI FUT8 \\
\hline GO:0004895 & cell adhesion receptor activity & $1.6 \%$ & CD44 TNC GPLDI ITGA4 \\
\hline GO:0015075 & ion transporter activity & $1.6 \%$ & TRPV2 SLC39A4 CP SLCI6A8 \\
\hline GO:0016301 & kinase activity & $1.2 \%$ & EPHA3 FLJ20559 NRPI \\
\hline GO:0030246 & carbohydrate binding & $0.8 \%$ & CHODL KLRBI \\
\hline GO:0005386 & carrier activity & $0.8 \%$ & A2M SLCI6A8 \\
\hline GO:0005 I80 & peptide hormone & $0.8 \%$ & PYY STC2 \\
\hline GO:0008565 & protein transporter activity & $0.8 \%$ & SORCS3 SCAMPI \\
\hline GO:0008I47 & structural constituent of bone & $0.8 \%$ & BGLAP COLIAI \\
\hline GO:0003800 & antiviral response protein activity & $0.4 \%$ & IFNGR2 \\
\hline GO:0008189 & apoptosis inhibitor activity & $0.4 \%$ & SPPI \\
\hline GO:0015457 & auxiliary transport protein activity & $0.4 \%$ & ENSA \\
\hline
\end{tabular}

Other factors such as FGF can play an angiogenic role. One FGF isoform was found significantly differential in some tumor combinations; FGF7 was elevated in colon and prostate xenograft tumors (1.5-fold, Pcorr $<8.7 \mathrm{e}-6$ and 3.7-fold, Pcorr $<7.5 e-7)$ respectively but 2 -fold suppressed in ovarian tumors (Pcorr <.006), Fig. 4. FGF7 was previously shown to stimulate the growth of endothelial cells of small but not large vessels in the rat cornea [39] and hence supports the notion of vascular remodeling versus vasculogenesis. That differential expression of this gene was found only in some tumor combinations is consistent with the concept that each type of tumor will display individual differences in the balance angiogenic activators and inhibitors, yet the end physiological result, increased tumor vascularization, is the same [3]. Finally, as noted above, genes that help destabilize or remodel vessels such as ANGPT2 and ANGPTL4 were induced, consistent with an overall pattern of late-stage angiogenesis.

\section{Linking angiogenic pathways to neuropeptide signaling pathways}

Additional support for the late, post-VEGF angiogenic pattern of gene expression in xenografts froms from the observed 5-fold induction of NPY1R by both ANOVA and linear discriminant analyses. NPY1R has been reported to play a role downstream of VEGF in vasoconstriction [40] and capillary sprouting and differentiation [41]. Consistent with the observation of NPY1R induction, the potent 


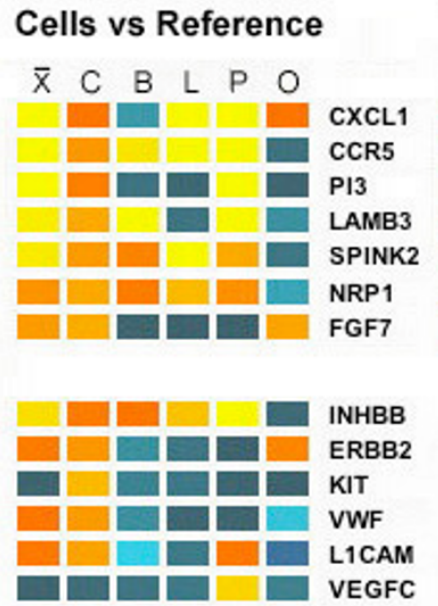

\section{Tumors vs Cells}

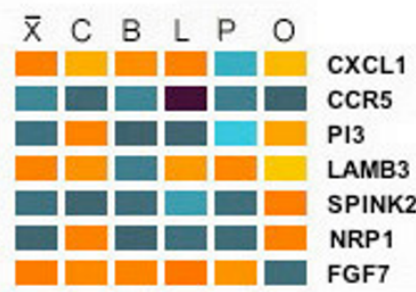

\author{
GO:0006950 chemokine (C-X-C motif) ligand 1 \\ GO:0007154 chemkine receptor 5 \\ GO:0019098 WAP four-disulfide core domain protein 14 \\ GO:0007154 laminin, beta 3 (nicein (125kD) \\ NA serine protease inhibitor, Kazal type, 2 \\ GO:0007397 neuropilin \\ GO:0009653 fibroblast growth factor 7 (keratinocyte growth factor)

Figure 4

Comparison of differential expression of genes in parental cells versus reference cDNA synthesized from universal RNA (left) and all tumors versus parental cell lines (right). Genes differentially expressed in the parental cells relative to the reference cDNA were analyzed by a 2-way ANOVA (Pcorr < .00I). A subset of the differentially expressed genes is shown. The corresponding cognate tumors with differential expression at a $99.9 \%$ confidence level by ANOVA analysis of tumors vs parental cell line data are shown. The heat maps indicate relative fold-induction or suppression in a linear colorencoded scale shown at the bottom. Mean ratios are indicated by $\mathrm{X}, \mathrm{C}=$ colon, $\mathrm{B}=$ breast, $\mathrm{L}=$ lung, $\mathrm{P}=$ prostate, $\mathrm{O}=$ ovary.

effect of ligand neuropeptide (NPY) upon angiogenesis was shown to yield branching vasodilated structures distinct from those generated by VEGF [17]. Similarly, neuropeptide $\mathrm{Y}$ has been reported to trigger angiogenesis via the NPY2 receptor in ischemic muscle of mice [41]. Interestingly, neuropilin 1 (NRP1) which can act as a co-receptor with VEGFR2 [42] was found suppressed (1.31-fold, Pcorr < .006) while other VEGF receptor levels were not significantly altered. Finally, previous expression profile studies have found NPY1R to be substantially induced in many breast, prostate and pancreatic carcinomas [28].

Additionally, two other differential genes involved in neuropeptide signaling were observed: melanocortin-2 receptor $(M C 2 R)$ and SORCS3/neurotensin receptor gene. Both $M C 2 R$ and the SORCS3 were found differentially expressed by ANOVA. MC2R is a GPCR that binds the ACTH peptide while SORCS3 is a homolog of the rat sortilin gene with VPS10 domains characteristic to neuropeptide-binding proteins [43-45]. ACTH has been found to increase angiogenesis of cultured endothelial cells in a 3D-collagen assay [19] and other neuropeptides have been implicated in stimulating VEGF in prostate cancer cells [46].

\section{Conclusion}

In this study we compared the expression profiles of secreted and cell surface genes from five different tissue sources. Multiple tumors were derived from each parental cell line to examine the potential for tumor heterogeneity arising from the primary isolate, but we found relatively consistent behavior within any tumor group. However, we also found tumor-specific genes for each tumor type while identifying a profile of genes shared amongst all tumor types by multiple analytical approaches. Overall, our results comprise a foundation of commonly regulated tumorigenic genes across tissues such as fundamental angiogenic inducers and regulators. Given the diverse and complex expression behavior of primary human tumors from any single tissue source $[27,28]$, in the future it will 


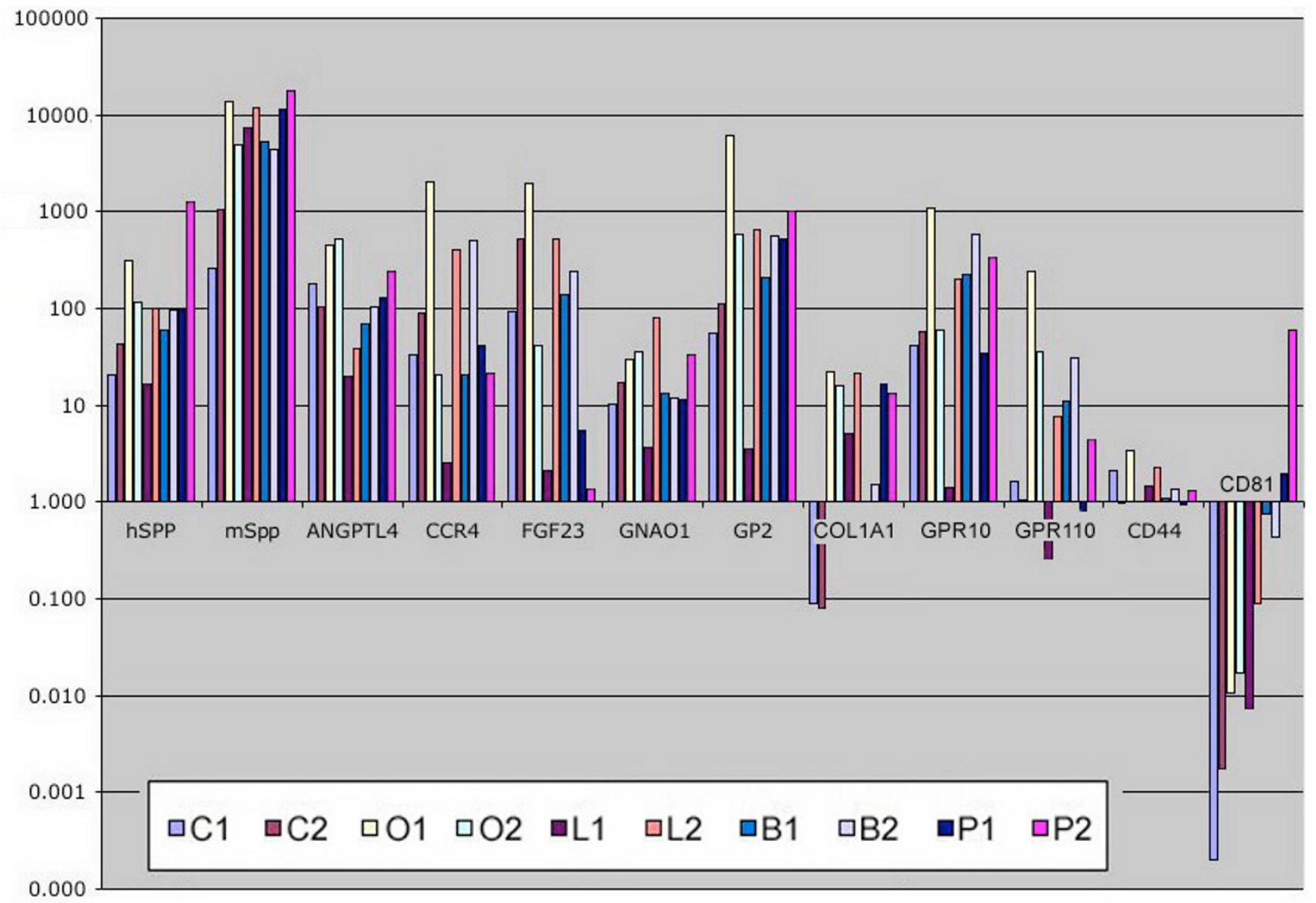

Figure 5

\section{Figure 5}

Quantitative PCR analysis of selected genes. Two tumors of each tumor type were analyzed by quantitative PCR. The measured fold change relative to cell line was determined. RNA amounts per well being normalized by betaactin signal. In general $<2$-fold changes are not significant. Hence a call of 1.5 fold down may not actually differ from I.5 up. Specific tumor types are indicated by the first initial followed by the tumor number: i.e. $\mathrm{CI}=$ colon tumor $\mathrm{\# I}, \mathrm{OI}=$ ovary tumor $\mathrm{\# I}, \mathrm{LI}=$ lung tumor $\mathrm{\# I}, \mathrm{BI}=$ breast tumor $\mathrm{\# I}, \mathrm{PI}=$ prostate tumor $\# \mathrm{I}$.

be necessary to examine several established lines from many histologically similar primary tumors as well as different tumor types from the same tissue. Similarly, it will be important to compare the effect of orthotopic implantation sites to the subcutaneous injection site in these preliminary studies. To resolve xenograft microheterogeneity, microarray analysis of micro-dissected xenograft or primary tumors can be used. Micro-dissection will also allow the assessment of potential vasculogenic mimicry by aggressive tumor cells that can express endothelial genes [38]. Additionally, the xenograft model can be more readily extended to monitor time-dependent expression profile changes in the development of tumors.
Such results can be used in combination or as a filter with other biomarker technologies such as tissue arrays [47] or mass spectroscopy [48] to fully characterize clinical specimens for diagnostic or prognostic purposes. By identifying genes known to participate in angiogenesis and tumorigenesis, our work establishes a baseline to evaluate and compare the full spectrum of gene profile changes in xenografts and clinical specimens. Hence, time and tissuespecific gene and protein profiles may be useful for the discovery of both biomarkers and new therapeutic strategies. 


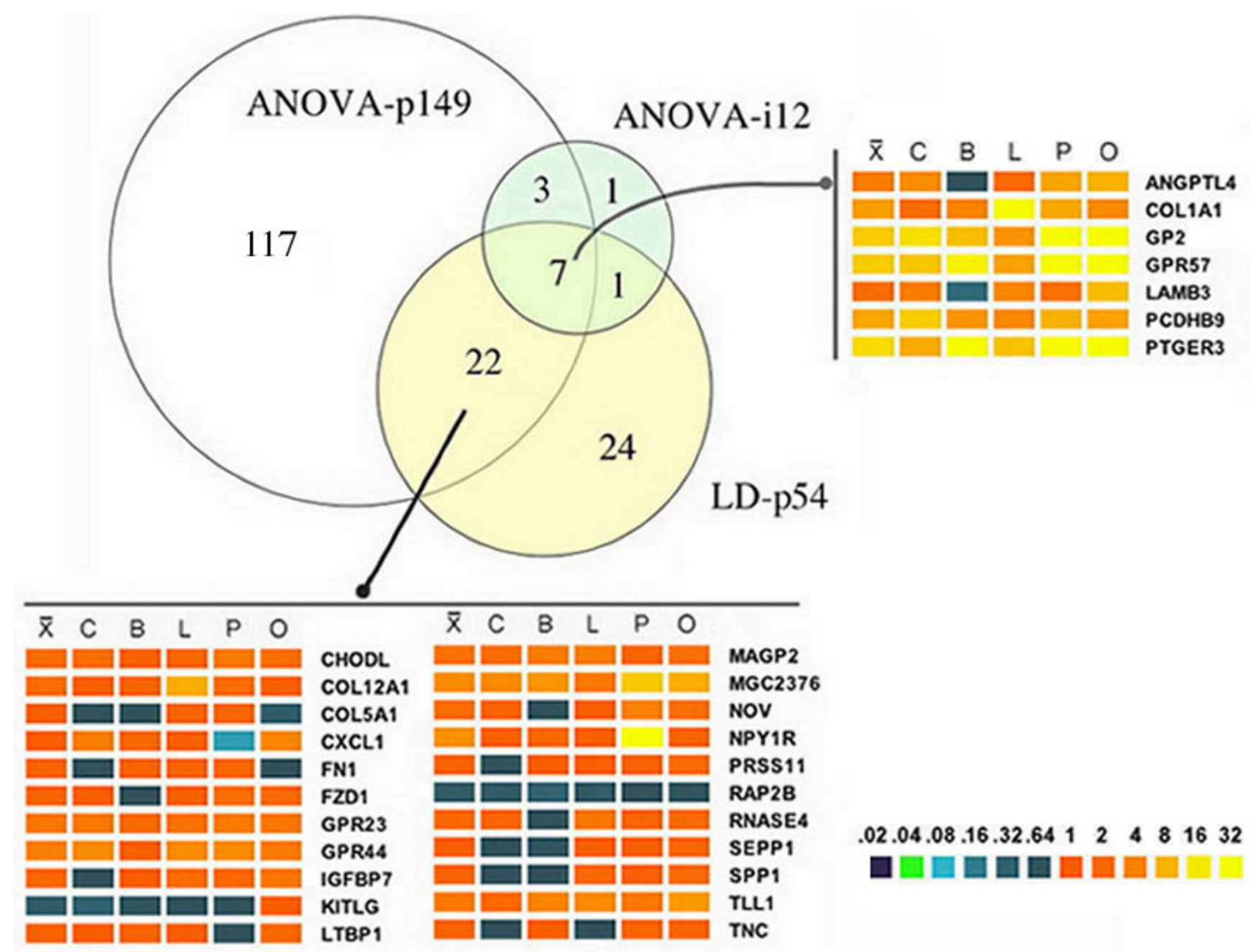

Figure 6

Figure 6

Overlap of differentially expressed genes identified by three analyses: ANOVA-p $\mid 49=149$ genes derived from the ANOVA analysis of all data, LD-p54 = linear discriminant list of 54 genes from all data, and ANOVA-i I $2=$ twelve genes resulting from a comparison of differentially expressed genes from the ANOVA analysis of individual tumors compared to parental cell lines. An estimate for the statistical significance for the overlap of differentially expressed genes by the 3 analytical methods was estimated by calculating the product of individual probabilities for the results of each analytical method applied to 353 I genes. The null hypothesis in this case is that each method's "call" as to a given gene's differential expression is independent of the call made by the other two methods. Thus if $\mathrm{pl}, \mathrm{p} 2$, and $\mathrm{p} 3$ represent the chance that each method calls a given gene as differentially expressed (easily estimated as number of genes called/ number of total genes), the chance that all three methods do so is simply pAll $=\mathrm{pl}^{*} \mathrm{p} 22^{*} \mathrm{p} 3=(54 / 353 I) *(\mid 49 / 353 I) *(\mid 2 / 353 I)=2.193 \mathrm{e}-5$. Under our null hypothesis, the total number of genes called by all three methods $k$ will follow a binomial distribution with parameters $p=p A l l, n=353 \mathrm{I}$ where $P(k=L) \sim$ $\operatorname{Bin}(p A l l, N)$. Standard calculation techniques allow us to calculate a $P$-value for this; i.e. $P=P(k>=K)-$ the chance under the null hypothesis we see as much or more overlap than was actually observed. For our data, we thus have $P=P(k>=7)<I E-6$. Thus, if the methods identified random noise as differential expression, they would be very unlikely to produce the overlap observed, thus supporting the statistical significance of the results. The heat maps indicate relative fold-induction or suppression in a linear color-encoded scale shown at the bottom. Mean ratios are indicated by $X, C=\operatorname{colon}, B=b r e a s t, L=l u n g, P=$ prostate, $\mathrm{O}=$ ovary. 


\section{Methods}

\section{Custom array design}

A two-stage strategy was employed to design the custom oligonucleotide microarray chip. First, for the known secreted and cell surface proteins, we performed keyword filtering of the gene descriptions and annotations of curated public databases such as SwissProt/Trembl [49], the Gene Ontology tables [23], the UCSC Human Genome assembly (hg13, NCBI Build 31 [50]), the GPCR database [51] and public gene tables from technical supply vendors (Affymetrix, Agilent and Illumina). Some of the keywords used were "secreted", "trans-membrane", "glycosylated" and "olfactory". Redundancies and false positives were removed by manual curation.

In order to accommodate continued optimization of a custom chip design, we chose a chip platform that met several criteria: it must allow rapid changes to the master template even for small production batches, possess relative high density, exhibit strong signal-to-noise properties and have high reproducibility $(\mathrm{CV}<10 \%)$. Hence, a custom oligonucleotide microarray chip (Agilent, Palo Alto, CA) was designed using the curated collection of secreted and cell surface proteins with human-specific 60-mer probes derived from the 3' 1500 nt region of each mRNA sequence. The custom chip was designed with a matrix of technical probe replicates and multiple probes for some genes; e.g. 2 or 3 probes with 1, 3 or 5 copies each per array represented some genes. All probes were curated by elimination of sequences with unfavorable Tm properties, predicted secondary structure or homo-polymer regions. Finally, Blastn [52] analysis was used to confirm human specificity by comparison to mouse sequences.

\section{Cell lines and mice}

All cell lines (A549, MDA MB-231, HCT-116, SK-OV3, and PC3) were obtained from the ATCC (Manassas, VA). Xenograft tumors were generated from each parental cell line by either implantation of cells or passage of a fragment from a primary tumor (Piedmont Research Center, Morrisville, NC). For the A549, MDA MB-231 and SKOV3 lines, le-7 cells grown with 10\% fetal calf serum in Dulbecco's modified Eagle's medium at $37^{\circ} \mathrm{C}$ in $5 \% \mathrm{CO}_{2}$ were implanted subcutaneously into the flank of between 8 and 10 BalbC (Harlan Labs, Indianapolis, IN) mice. Between 50 and $75 \%$ of the mice yielded a palpable primary xenograft tumor. For the HCT116 and PC3 xenograft tumors, $1 \mathrm{~mm}^{3}$ tumor fragments between $103-110 \mathrm{mg}$ were excised from a primary xenograft tumor and passaged into secondary mice for the HCT-116 and PC3 xenograft tumors. For PC3 tumors, 8 male mice were implanted with fragments; otherwise recipient mice were female. The number of tumors processed for hybridization were 5 for SK-OV-3, 5 for PC3, 4 for MDA MB-231, 3 for HCT-116 and 5 for A549.

\section{RNA preparation}

For the parental cell lines, total RNA was harvested from 4 x 106 cells using a High Pure RNA isolation kit (Roche Applied Science, Indianapolis, IN) according to manufacturer's instructions. Tumors were excised 22-29 days postimplantation under accredited procedures (Piedmont Research Center, Morrisville, NC), snap-frozen in liquid nitrogen and stored at $-80^{\circ} \mathrm{C}$ until use. Total RNA was prepared from frozen specimens by $24 \mathrm{hr}$ immersion at $80^{\circ} \mathrm{C}$ in RNAlater-ICE (Ambion, Austin, TX) to 'transition' solid tumors for subsequent homogenization by grinding with a liquid nitrogen-chilled mortar/pestle, followed by resuspension in Trizol (Sigma-Aldrich, E. St. Louis, Mo) and sonication to complete the tissue disruption. Total RNA was extracted using Phase-lock gels (Brinkmann, Westbury, NY), ethanol precipitated, resuspended in RNase-free water, and aliquoted prior to use. Quality control of the total RNA was facilitated by the use of a microcapillary electrophoresis system (Agilent 2100 Bioanlyzer; Agilent Technologies, Palo Alto, CA).

\section{Experimental design and array hybridization}

To identify cell surface genes that are consistently differentially regulated amongst the derivative tumors, multiple tumor specimens and their parental source cell lines were hybridized to the custom chips. All biological specimens were co-hybridized with a reference cDNA synthesized from mRNA that is mixture of 10 human established cell lines (Universal RNA; Stratagene, Carlsbad, CA). For each array, amino-allyl labeled single-stranded cDNA was synthesized from 10 ( $\mathrm{g}$ of sample total RNA and from $10 \mathrm{ug}$ universal RNA using the Agilent Fluorescent Direct Label Kit according to manufacturer's instructions, except that a dNTP mix containing 5-[3-Aminoallyl]-2'-deoxyuridine 5'-triphosphate (AA-dUTP; Sigma-Aldrich) was used (final concentration: 100 (M dATP, dCTP, dGTP; 50 (M dTTP, AA-dUTP). Amino-allyl labeled cDNA was purified using QIAquick PCR columns (Qiagen, Valencia CA) and coupled to either N-hydroxysuccinimidyl-esterified Cy3 or Cy5 dyes (Cy-Dye mono-functional NHS ester; Amersham, Piscataway NJ). Dye-conjugated cDNAs were purified from free dye using the CyScribe GFX purification kit (Amersham). Targets were hybridized to the microarray for 16 hrs at $60^{\circ} \mathrm{C}$ using an Agilent In Situ Hybridization Kit per manufacture's instructions, washed $10 \mathrm{~min}$ in $6 \times$ SSC, $0.005 \%$ Triton $\mathrm{X}-102$ at $22^{\circ} \mathrm{C}, 0.1 \times$ SSC, $0.005 \%$ Triton $\mathrm{X}-102$ for $10 \mathrm{~min}$ at $4^{\circ} \mathrm{C}$, dried under a stream of nitrogen, and scanned with an Agilent Microarray Scanner. Hybridization signals were extracted with Agilent Feature Extraction Software version 7.1, which yielded the median of all pixel intensities for each feature. Since two identical arrays of 8500 features were printed on each chip, a complete dye-swap comparison could be performed per chip. For example, on the left array, a Cy3labeled biological specimen was co-hybridized with Cy5- 
labeled cDNA made from universal RNA. For the cognate dye-swap experiment on the right array, a Cy-5 labeled biological specimen was co-hybridized with Cy3-labeled cDNA made from universal RNA. No tumor samples were mixed with any other tumors.

To enable identification of differentially expressed genes with higher statistical reliability, we performed a matrix of hybridizations. The hybridization matrix follows: for the 5 SK-OV-3, A549 and PC3 tumor specimens, 3 of the tumor samples were hybridized to 2 chips each (hence 4 arrays per tumor sample) while 2 tumor samples were hybridized to a 1 chip each (hence 2 arrays for each of these tumors). For the 4 MDA MB-231 tumor specimens, 3 of the tumor samples were hybridized to 2 chips each and 1 tumor was hybridized to a single chip of 2 arrays. For the 3 HCT-116 tumor specimens, all 3 tumors were hybridized to 2 chips each ( 4 arrays each). For the parental cell lines, HCT-116 cells were hybridized to 6 chips (12 arrays) while the other cell lines were hybridized to 2 chips each (4 arrays). Since most probes were present minimally in triplicate on each array, whenever a tumor sample was hybridized to 2 chips $n=\left(3^{*} 4\right)=12$ per probe. However, since dye-swap hybridizations were routinely performed, $\mathrm{n}=6$ for the Cy 3 and Cy5 signals respectively.

\section{Quantitative PCR}

Real-time (RT-) PCR analysis of selected RNA transcripts was performed using either a GeneAmp 5700 Sequence Detection System or an ABI PRISM 7900HT Sequence Detection System with SyBr green chemistry (Applied Biosystems, Foster City, CA). The cDNA produced by reverse transcribing the equivalent of 10 ng of total RNA was loaded per RT-PCR reaction. The following primers pairs were used: beta actin (ACTB) CCTGGCACCCAGCACAAT, GCCGATCCACACGGAGTACT; Human osteopontin (HSPP) AGCAAAATGAAAGAGAACATGAAATG, TTCAACCAATAAACTGAGAAAGAAGC; murine osteopontin ( $m S p p)$ ATTTTGGGCTCTTAGCTTAGTCTGTT, GGTTACAACGGTGTTTGCATGA; angiopoietin-like 4 (ANGPTL4)ATGTGGCCGTTCCCTGC, TCTTCTCTGTCCACAAGTTTCCAG; chemokine (C-C motif) receptor 4 (CCR4)ATTCCTGAGCCAGTGTCAGGAG, CTGTCTTTCCACTGTGGGTGTAAG; fibroblast growth factor 23 (FGF23)GGCAAAGCCAAAATAGCTCC, CTGCCACATGACGAGGGATAT; G protein, alpha activating activity polypeptide O (GNAO1) CTAGTCTTTGGGAAACGGGTTGT, AAATCCAACACGGCAAAGGA; glycoprotein 2 (GP2) GCTTTCCACTCCAATTCACACA, CCTGGCCTTGATTCTGTTAATACC; collagen, type I, alpha 1 (COL1A1)TCCCCAGCTGTCTTATGGCT, CAGCACGGAAATTCCTCC; G protein-coupled receptor 10 (GPR10)CATGCTCGAGTCATCAGCCA, TTTCACTGCCCCCTTTGTGT; G protein-coupled receptor 110
(GPR110)AAGCTCTGGAGGCCGACTG， GGCCTTGTCATCCCGACTC; (CD44)TACAGCATCTCTCGGACGGAG, GGTGCTATTGAAAGCCTTGCA; (CD81)CCCTAAGTGACCCGGACACTT, CGTTATATACACAGGCGGTGATG. The identity of each amplicon was confirmed by melting curve analysis at the end of the RTPCR run.

\section{Array analysis}

While the array vendor's feature extraction software 'processed' the hybridization signal to correct for image intensity, background and minor spatial artifacts, chip-to-chip comparisons such as 'reference' versus 'experimental' sample were handled by a custom database [25] built in MySQL [53] with a web interface served by Apache [54]. The database allows the control of experimental design and specification of comparisons and analyses to be performed. Some calculations, like T-Tests and ratios, can be performed in the database or its interface layer, but MATLAB (Mathworks, Natick, MA) was used for ANOVA and principal components analysis (PCA).

For identification of differentially expressed genes, we used the MAANOVA package [55] an implementation of ANOVA for microarray analysis [24]. Array data were loaded into the database and minimally pre-processed for use with this package: where replicate features of the same probe existed in the array design, an arithmetic mean was calculated to yield a single expression level for each probe for each chip. Each tumor or cell line sample was hybridized to 3 separate chips. All signals were Log2 transformed prior to subsequent analyses. These data were used to fit a linear model with factors Gene, Array, Array $\times$ Gene, Dye, Dye $\times$ Gene, and Sample $\times$ Gene. This last attribute is the quantity used for analysis, representing the differential expression of a given gene under a given experimental condition, with the other factors serving to normalize the data. In order to identify differential expression these residuals were analyzed with three statistical tests: a standard ANOVA F-test and two minor variations. A probe had to pass these three tests, generally at $99.9 \%$ significance, in order to be called as differentially expressed. A permutation analysis and one-step multiple comparisons correction were applied in conjunction with these tests. It should be noted that since three tests are applied, three Pvalues result, and when single P-values are listed; the maximum of the three P-values is reported. Finally, since all samples were co-hybridized with cDNAs made from a universal RNA sample, for comparisons of differential gene behavior, approximate 'ratios' were calculated by dividing the paired individual tumor/universal RNA ratio by the paired parental cell/universal RNA ratio. 


\section{Ontology annotation}

Unigene Gene names were classified by the consistent terms of the Gene Ontology(tm) consortium [23] and the fatiGO interface to the Gene Ontology [56].

\section{Authors' contributions}

RAS helped design and implement the experimental strategy by developing many protocols, carried out many of the hybridization experiments and analyzed the PCR data. RT carried out the sample preparation, labelings, microarray and PCR experiments. SK performed the statistical analysis and assisted database design. SO designed and built the microarray database and LIMs. RH and YL helped curate, annotate and design the custom microarray chip design. $\mathrm{CN}$ carried out the xenograft studies. AA conceived of the experimental design. DJC designed \& managed the experimental strategy, helped curate the gene lists and wrote the manuscript with input from coauthors.

\section{Acknowledgements}

This work was completed in collaboration with Surromed, Mountain View, CA. We also wish to acknowledge the helpful comments of Beth Hollister of the Piedmont Research Center, Morrisville, NC.

\section{References}

I. Paget S: The distribution of secondary growths in cancer of the breast. Lancet 1889, I:57|-3.

2. Khong HT, Restifo NP: Natural selection of tumor variants in the generation of "tumor escape" phenotypes. Nat Immunol 2002, 3:999-1005.

3. Bergers G, Benjamin LE: Tumorigenesis and the angiogenic switch. Nat Rev Cancer 2003, 3:40I-I0.

4. Glinsky GV, Krones-Herzig A, Glinskii AB, Gebauer G: Microarray analysis of xenograft-derived cancer cell lines representing multiple experimental models of human prostate cancer. Mol Carcinog 2003, 37:209-2I.

5. Pedersen N, Mortensen S, Sorensen SB, Pedersen MW, Rieneck K, Bovin LF, Poulsen HS: Transcriptional gene expression profiling of small cell lung cancer cells. Cancer Res 2003, 63:1943-53.

6. Creighton C, Kuick R, Misek DE, Rickman DS, Brichory FM, Rouillard JM, Omenn GS, Hanash S: Profiling of pathway-specific changes in gene expression following growth of human cancer cell lines transplanted into mice. Genome Biol 2003, 4:R46.

7. Perou CM, et al:: Molecular portraits of human breast tumours. Nature 2000, 406:747-52.

8. Dhanasekaran SM, Barrette TR, Ghosh D, Shah R, Varambally S, Kurachi K, Pienta KJ, Rubin MA, Chinnaiyan AM: Delineation of prognostic biomarkers in prostate cancer. Nature 200I, 4I 2:822-6.

9. Fidler IJ: The pathogenesis of cancer metastasis: the "seed and soil" hypothesis revisted. Nature Reviews 2003, 3:453-8.

10. Holash J, Wiegand SJ, Yancopoulos GD: New model of tumor angiogenesis: dynamic balance between vessel regression and growth mediated by angiopoietins and VEGF. Oncogene 1999, 18:5356-62.

II. Vajkoczy P, Farhadi M, Gaumann A, Heidenreich R, Erber R, Wunder A, Tonn JC, Menger MD, Breier G: Microtumor growth initiates angiogenic sprouting with simultaneous expression of VEGF, VEGF receptor-2, and angiopoietin-2. J Clin Invest 2002, 109:777-85.

12. Benjamin LE, Hemo I, Keshet E: A plasticity window for blood vessel remodelling is defined by pericyte coverage of the preformed endothelial network and is regulated by PDGF-B and VEGF. Development 1998, 125:159|-8.

13. Gerhardt $\mathrm{H}$, Betsholtz C: Endothelial-pericyte interactions in angiogenesis. Cell Tissue Res 2003, 3 14:15-23.
14. Shirakawa K, Wakasugi H, Heike Y, Watanabe I, Yamada S, Saito K, Konishi F: Vasculogenic mimicry and pseudo-comedo formation in breast cancer. Int J Cancer 2002, 99:82I-8.

15. Aonuma M, Iwahana M, Nakayama Y, Hirotani K, Hattori C, Murakami K, Shibuya M, Tanaka NG: Tumorigenicity depends on angiogenic potential of tumor cells: dominant role of vascular endothelial growth factor and/or fibroblast growth factors produced by tumor cells. Angiogenesis 1998, 2:57-66.

16. Hattori K, et al.: Vascular endothelial growth factor and angiopoietin-I stimulate postnatal hematopoiesis by recruitment of vasculogenic and hematopoietic cells. J Exp Med 200I, 193:1005-14.

17. Ekstrand AJ, Cao R, Bjorndahl M, Nystrom S, Jonsson-Rylander AC, Hassani $H$, Hallberg B, Nordlander M, Cao Y: Deletion of neuropeptide $Y$ (NPY) 2 receptor in mice results in blockage of NPY-induced angiogenesis and delayed wound healing. Proc Natl Acad Sci USA 2003, 1 00:6033-8.

18. Maeshima Y, Colorado PC, Torre A, Holthaus KA, Grunkemeyer JA, Ericksen MB, Hopfer H, Xiao Y, Stillman IE, Kalluri R: Distinct antitumor properties of a type IV collagen domain derived from basement membrane. J Biol Chem 2000, 275:21340-8.

19. Mallet C, Feraud O, Ouengue-Mbele G, Gaillard I, Sappay N, Vittet D, Vilgrain I: Differential expression of VEGF receptors in adrenal atrophy induced by dexamethasone: a protective role of ACTH. Am J Physiol Endocrinol Metab 2003, 284:EI 56-67.

20. Giard DJ, Aaronson SA, Todaro GJ, Arnstein P, Kersey JH, Dosik H, Parks WP: In vitro cultivation of human tumors: establishment of cell lines derived from a series of solid tumors. J Natl Cancer Inst 1973, 5 I: |417-23.

21. Cailleau R, Young R, Olive M, Reeves WJ: Breast tumor cell lines from pleural effusions. J Natl Cancer Inst 1974, 53:66I-74.

22. Kaighn ME, Narayan KS, Ohnuki Y, Lechner JF, Jones LW: Establishment and characterization of a human prostatic carcinoma cell line (PC-3). Invest Urol 1979, 17:16-23.

23. Gene Ontology [http://wwwgeneontology.org/]

24. Kerr MK, Churchill GA: Experimental design for gene expression microarrays. Biostatistics 200I, 2:|83-20|.

25. Osborn S, Kennedy S, Chin D: A flexible pipeline for experimental design processing and analysis of microarray data. In IEEE Comp Systems Bioinformatics IEEE Computer Society, Los Alamitos, CA; 2003:4II-4I2.

26. Lenburg ME, Liou LS, Gerry NP, Frampton GM, Cohen HT, Christman MF: Previously unidentified changes in renal cell carcinoma gene expression identified by parametric analysis of microarray data. BMC Cancer 2003, 3:31.

27. Perou $\mathrm{CM}$, et al.: Distinctive gene expression patterns in human mammary epithelial cells and breast cancers. Proc Natl Acad Sci USA 1999, 96:9212-7.

28. Su Al, et al:: Molecular classification of human carcinomas by use of gene expression signatures. Cancer Res 200I, 61:7388-93.

29. Yoon JC, Chickering TW, Rosen ED, Dussault B, Qin Y, Soukas A, Friedman JM, Holmes WE, Spiegelman BM: Peroxisome proliferator-activated receptor gamma target gene encoding a novel angiopoietin-related protein associated with adipose differentiation. Molec Cell Biol 2000, 20:5343-5349.

30. Le Jan S, et al.: Angiopoietin-like $\mathbf{4}$ is a proangiogenic factor produced during ischemia and in conventional renal cell carcinoma. Am J Pathol 2003, I62:152 I-8.

31. Yoshida K, Shimizugawa T, Ono M, Furukawa H: Angiopoietin-like protein $\mathbf{4}$ is a potent hyperlipidemia-inducing factor in mice and inhibitor of lipoprotein lipase. J Lipid Res 2002, 43: 1770-2.

32. Harada S, Nagy JA, Sullivan KA, Thomas KA, Endo N, Rodan GA, Rodan SB: Induction of vascular endothelial growth factor expression by prostaglandin E2 and EI in osteoblasts. J Clin Invest 1994, 93:2490-6.

33. Gallo O, Franchi A, Magnelli L, Sardi I, Vannacci A, Boddi V, Chiarugi $\mathrm{V}$, Masini E: Cyclooxygenase-2 pathway correlates with VEGF expression in head and neck cancer Implications for tumor angiogenesis and metastasis. Neoplasia 2001, 3:53-61.

34. Fukuda R, Kelly B, Semenza GL: Vascular endothelial growth factor gene expression in colon cancer cells exposed to prostaglandin E2 is mediated by hypoxia-inducible factor I. Cancer Res 2003, 63:2330-4.

35. Oh Y, Nagalla SR, Yamanaka Y, Kim HS, Wilson E, Rosenfeld RG: Synthesis and characterization of insulin-like growth factorbinding protein (IGFBP)-7 Recombinant human mac25 pro- 
tein specifically binds IGF-I and -II. I Biol Chem 1996, 27I:30322-5.

36. Yamauchi T, Umeda F, Masakado M, Isaji M, Mizushima S, Nawata H: Purification and molecular cloning of prostacyclin-stimulating factor from serum-free conditioned medium of human diploid fibroblast cells. Biochem J 1994, 303:591-8.

37. Carson-Walter EB, Watkins DN, Nanda A, Vogelstein B, Kinzler KW, St Croix G: Cell surface tumor endothelial markers are conserved in mice and humans. Cancer Res 200I, 61:6649-55.

38. Hendrix MJ, Seftor EA, Hess AR, Seftor RE: Molecular plasticity of human melanoma cells. Oncogene 2003, 22:3070-5.

39. Gillis P, Savla U, Volpert OV, Jimenez B, Waters CM, Panos RJ, Bouck NP: Keratinocyte growth factor induces angiogenesis and protects endothelial barrier function. J Cell Sci 1999, I I 2:2049-57.

40. Zukowska-Grojec Z, Dayao EK, Karwatowska-Prokopczuk E, Hauser G], Doods HN: Stress-induced mesenteric vasoconstriction in rats is mediated by neuropeptide $Y$ YI receptors. Am J Physiol 1996, 270:H796-800.

4l. Lee EW, et al:: Neuropeptide $\mathbf{Y}$ induces ischemic angiogenesis and restores function of ischemic skeletal muscles. J Clin Invest 2003, I II:I853-62.

42. Soker S, Takashima S, Miao HQ, Neufeld G, Klagsbrun M: Neuropilin-I is expressed by endothelial and tumor cells as an isoform-specific receptor for vascular endothelial growth factor. Cell 1998, 92:735-45.

43. Hampe W, Rezgaoui M, Hermans-Borgmeyer I, Schaller HC: The genes for the human VPSIO domain-containing receptors are large and contain many small exons. Hum Genet 200I, 08:529-36.

44. Lintzel J, Franke I, Riedel IB, Schaller HC, Hampe W: Characterization of the VPSIO domain of SorLA/LRII as binding site for the neuropeptide HA. Biol Chem 2002, 383: 1727-33.

45. Vincent JP, Mazella J, Kitabgi P: Neurotensin and neurotensin receptors. Trends Pharmacol Sci 1999, 20:302-9.

46. Levine L, Lucci JA, Pazdrak B, Cheng JZ, Guo YS, Townsend CM, Hellmich MR: Bombesin stimulates nuclear factor kappa B activation and expression of proangiogenic factors in prostate cancer cells. Cancer Res 2003, 63:3495-502

47. Hoos A, Urist MJ, Stojadinovic A, Mastorides S, Dudas ME, Leung DH, Kuo D, Brennan MF, Lewis JJ, Cordon-Cardo C: Validation of tissue microarrays for immunohistochemical profiling of cancer specimens using the example of human fibroblastic tumors. Am J Pathol 200I, 158:1245-5I.

48. Petricoin EF, et al: Use of proteomic patterns in serum to identify ovarian cancer. Lancet 2002, 359:572-7.

49. Swiss-Prot [http://www.expasy.org/sprot/]

50. UCSC Genome [http://www.genome.ucsc.edu/]

51. GPCR Database [http://www.gpcr.org]

52. NIH Blast [http://www.ncbi.nlm.nih.gov/blast]

53. MySQL [http://sourceforge.net/projects/mysql]

54. Apache [http://www.apache.org]

55. Maanova Tools [http://www.jax.org/staff/churchill/labsite/software/ anova/rmaanova/]

56. FatiGO [http://fatigo.bioinfo.cnio.es/]

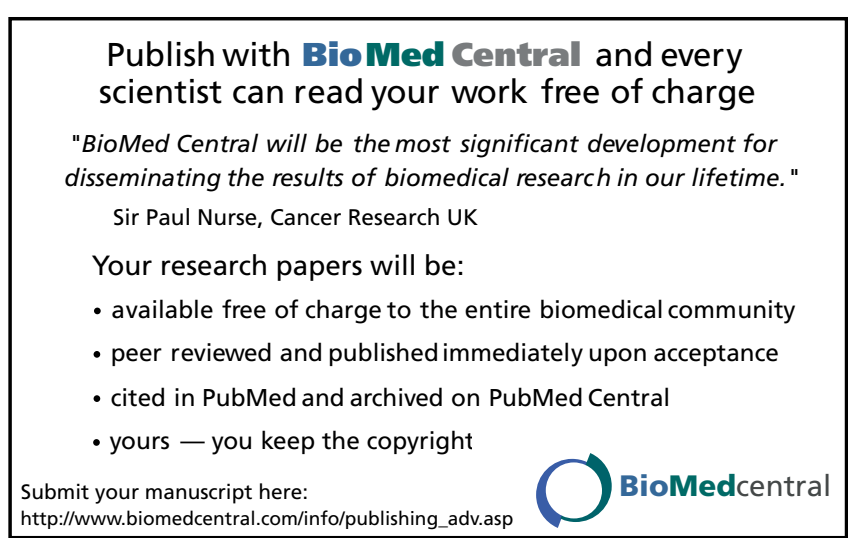

